\title{
Investigating the Effect of Loading Curcuminoids Using PCL-PU-BCD Nano-Composites on Physico-Chemical Properties, In-Vitro Release, and Ex-Vivo Breast Cancer Cell-Line
}

\author{
Sally A. Abou Taleb ${ }^{1, *}$, Rokaya A. Sobh ${ }^{2}$, Reda M. Mourad ${ }^{2, * i D}$ \\ 1 Pharmaceutical Technology Department, National Research Centre, Dokki, Cairo, Egypt \\ 2 Polymers and Pigments Department, National Research Centre, Dokki, Cairo, Egypt \\ * Correspondence: redamourad14@gmail.com; aboutaleb2012@gmail.com;
}

Scopus Author ID 42060956400

Received: 7.06.2021; Revised: 15.07.2021; Accepted: 18.07.2021; Published: 13.08.2021

\begin{abstract}
Recently, cancer is deemed the main reason for death. Although most anti-cancer drugs have potent anti-cancer activity, their applications are greatly obstructed due to their flimsy solubility, stability, and high toxicity. Nanotechnology is considered the major distinctive tool for achieving highly safe and effective drug-delivery carriers. This survey studied the synthesis of poly-caprolactone polyurethane $\beta$-cyclodextrin (PCL-PU- $\beta C D$ ) amphiphilic copolymer and using such polymer with synthesized C5-curcuminoids as drug type to prepare polymeric-nano micelles by following two modified techniques, with confirming the synthesis of C5-curcuminoids, PCL, and PCL-PU- $\beta C D$, and the formation of polymeric-nanocomposites plus studying the formed nanocomposites; encapsulations, release patterns and kinetics, morphologies, physico-chemical properties and finally evaluating the death efficacy of these Curcuminoids-PCL-PU- $\beta C D$ polymeric-nanocomposites on cancer cell cultures. The research results showed a successfully prepared C5-curcuminoid drug, PCL-PU- $\beta C D$ polymer and Curcuminoids-PCL-PU- $\beta C D$ polymeric-nanocomposites revealing; adequate encapsulations, controlled sustained releasing, promising physico-chemical properties, low cytotoxicity, and an auspicious $\mathrm{IC}_{50} \%$ on breast tumor cell-culture that were higher for the second preparation technique nanocomposites comparatively to the first preparation technique, despite such variation, both preparation techniques resulted in variances that were not significantly different $(p>0.05)$.
\end{abstract}

Keywords: PCL based polyurethane, $\beta$-cyclodextrin, synthesized C5-curcuminoids, vesico-micelle nano-drug delivery systems, prolonged-release, breast cancer.

(C) 2021 by the authors. This article is an open-access article distributed under the terms and conditions of the Creative Commons Attribution (CC BY) license (https://creativecommons.org/licenses/by/4.0/).

\section{Introduction}

Biodegradable polymers are versatile and widely applied mainly in the biomedical fields such as surgical implants, packaging, and controlled drug delivery systems [1]. Polyurethanes are polymers possessing unique properties like biocompatibility and biodegradability, making them used in the biomedical field as a biomaterial, elastomeric product, drug delivery, and shape memory material [2]. The urethane linkages, responsible for the hard segment, are formed by the reaction of the isocyanate groups with the hydroxyl group of other constituents. Polyurethane (PU) is generally synthesized by reacting diisocyanate terminated pre-polymer with chain extender having hydroxyl or amine functional groups $[3,4]$. 
The poly ( $\varepsilon$-caprolactone) (PCL) based PU that is the soft segment has been extensively investigated.

PCL is a promising biomaterial with an excellent curative potential attributed to its high drug permeability, perfect biocompatibility, and excreted from the body [5-7].

On the other hand, $\beta$-cyclodextrin $(\beta C D)$ is a cyclic oligosaccharide, seven Dglucopyranose residues linked by a-1,4-glycosidic bonds, produced from starch by the mean of enzymatic conversion $[8,9]$. Due to low toxicity and certain hydrophilicity, $\beta C D$ is widely used for drug delivery [10,11]. $\beta C D$ has both a hydrophobic internal cavity and a hydrophilic exterior $[9,12,13]$. $\beta C D$ can form a complex because of their suitable cavity sizes and acts as a functional carrier material. Complexation with $\beta C D$ provides a way to increase drugs' solubility, stability, and bioavailability $[11,14,15]$. In previous studies, $\beta C D$ has been introduced into PUs. Du, Song, Yang, Wu, Ma and Gao [8] synthesized PUs based on 1,6hexamethylene diisocyanate (HDI) and poly(ethylene glycol) ( (PEG) of different molecular weights with/without end-capped heptakis (2,6-di-O-methyl)- $\beta$-cyclodextrin (DM- $\beta$-CD) and found that, PUs containing DM- $\beta-C D$ exhibited higher protein encapsulation efficiency (EE) and loading capacity (LC) than those without DM- $\beta-C D$.

Both $\beta C D$ and PCL are distinguished as safe, biodegradable polymeric candidates that were approved by Food and Drug Administrations, with a distinct sustained delivery of many therapeutic substances when used in diverse drug delivery systems for biomedical treatments [16-19].

C5-curcuminoids (bis(aryl methylidene)acetones) have promoted several researches due to their intrinsic biological activities such as anti-HIV [20], antioxidant [21-23], antiinflammatory [21,24] and antitumor activities [21,25,26]. Liang, Shao, Wang, Zhao, Chu, Xiao, Zhao, Li and Yang [25] studied the in vitro stability and the in vivo pharmacokinetics of C5-curcuminoids and indicated that these C5-curcuminoids were stable greatly and their in vivo pharmacokinetics were also obviously enhanced. As well, some researchers reported that C5-curcuminoids are more potent than curcumin [25,27]. Yamakoshi, Ohori, Kudo, Sato, Kanoh, Ishioka, Shibata and Iwabuchi [28] manifested that bis(aryl methylidene) acetone skeletons are considered the most active structure was exhibiting cytotoxicity. Curcuminoids available from natural food ingredients have been found as an efficient anti-breast cancer agent targeting the estrogen receptors [29]. Intercalation of chemical synthesis allowed indicating the bioactive metabolites and helped in understanding the potential of these natural products, including curcumin as an anti-cancer agent. Al-Hujaily, Mohamed, Al-Sharif, Youssef, Manogaran, Al-Otaibi, Al-Haza'a, Al-Jammaz, Al-Hussein and Aboussekhra [30] found that 4-hydroxy-3-methoxybenzylidene)- N-methyl-4-piperidone (PAC), which is the analogue of curcumin, has a powerful anti-tumor effect against breast cancer. Somers-Edgar, Taurin, Larsen, Chandramouli, Nelson and Rosengren [31] reported that the heterocyclic cyclohexanone derivative of curcumin enhanced the cytotoxic potency towards estrogen receptor-negative breast cancer cells. However, C5-curcuminoid analogs as curcumin are hydrophobic and still have bioavailability obstacles such as absorption, distribution, metabolism, etc. Insertion of hydrophobic drugs within polymeric biodegradable nanoformulations like; nanoemulsions, nanospheres, and nanoparticles, resulting in the main alteration of drugs chemical and physical properties, causing; improvement in these drugs bioavailability [32-34], prolonging their circulation time and enhancing their selectivity to tumor cells [35-39] with facilitating their cellular uptake and reducing normal cells cytotoxicity [40-42]. PCL-based nano-drug delivery formulations showed a promising efficacy of targeting 
and controlling the drugs delivery, high crossing ability toward different physiological barriers, and minimizing the systemic side-effects [43-45].

PCL could be copolymerized or even blended with other polymers in order to obtain fascinating characteristics, including efficient loading of drug and effective releasing properties [46-48]. As, documented by Choi, Chae, and Nah [49], PCL-block copolymer nanoparticles implemented an obvious enhancement of drug encapsulation, delaying the drug release and achieving the desired drug release manner. Also, Prabu, Chaudhari, Dharmaraj, Khil, Park, and Kim [50] loaded vinblastine within a newly prepared PCL co-polymeric nanoparticles, where the drug in-vitro anti-cancer activity results estimated on breast cancer cell line showed an efficacious anti-cancer action of such prepared nanoparticle.

PCL-polyurethane block copolymers within an alternating controlled regular arrangement block fashion possessed a well-controlled and defined chemical structure along with an advantageous microstructure. The regularly structured endow substances with especially fascinating properties, such as efficient biocompatibility, shape-forming, and mechanical biodegradability properties, giving these copolymers a bonus capacity in advanced applications [51]. Moreover, the documented biological tests showed that PCL-polyurethane block copolymers could optimize the hema-compatibility and cause fine cell compatibility, growth, attachment, and proliferation in rats cells making such copolymers suitable safe candidates for internal medical applications [51].

And as the main concern of such a survey was to fulfill the future perspectives, which adopt the principle that encapsulating various bioactive molecules/drugs into PCL copolymeric-based nano-carriers facilitates targeted and sustained delivery of drugs in various biomedical applications in order to achieve an effective therapeutic potential.

Therefore, this research synthesized PCL by ring-opening of $\varepsilon$-caprolactone, followed by PCL-based PU preparation using HDI and $\beta C D$ as hard segments and chain extender, respectively. Pursuing this study's goal was to encapsulate the synthesized C5-curcuminoids bis(arylmethylidene)acetones in new nanoparticle formulations using the synthesized PCL-PU$\beta C D$ polymer where such Curcuminoids-loaded nanocomposites potential as anti-breast cancer delivery system was evaluated.

\section{Materials and methods}

\subsection{Materials.}

$\varepsilon$-Caprolactone ( $\varepsilon$-CL) monomer was purchased from Aldrich Chemical Co., dried over calcium hydride for 24 hours at room temperature, and purified by vacuum distillation in a nitrogen atmosphere. The fraction collected under reduced pressure $(<5 \mathrm{~mm} \mathrm{Hg})$ at $94-98{ }^{\circ} \mathrm{C}$ was used for polymerization. HDI was supplied from Aldrich Chemical Co. and used as received. 1,4-butandiol was obtained from Merck Co. and dried on a rotary evaporator for 4 hours at $85^{\circ} \mathrm{C}$ under reduced pressure. N,N-Dimethyl formamide (DMF) was dried over calcium hydride and distilled under a vacuum before use. Stannous octoate [Sn(oct)2] used as catalysts were of analytical grade and purchased from Merck Co. $\beta$-cyclodextrin $(\beta C D$, Kleptose) was supplied from Roquette Co., kept in a vacuum desiccator in the presence of $\mathrm{P} 2 \mathrm{O} 5$, and dried a rotary evaporator for $6 \mathrm{~h}$ at $90^{\circ} \mathrm{C}$ under reduced pressure before use. Acetone was supplied by Carl Roth Co. Curcumin (Cur) was supplied by Loba Chemie Co. Benzenaldyde was supplied by Merck Co. Thiophene-2- carbaldyde was purchased from Aldrich Chemical Co. Oleic acid was purchased from El Nasr Pharmaceutical Co., Egypt. 
Tween 80 and Pluronic F68 were obtained from Sigma Co., and all solvents used were of analytical grade.

\subsection{Experiments.}

\subsubsection{Synthesis of PCL diol.}

$\varepsilon$-CL (50 g, $0.438 \mathrm{~mol})$, 1,4-butandiol (1.127 g, $0.0125 \mathrm{~mol})$ and four drops of stannous octoate were added in a $250 \mathrm{~mL}$ three-necked round-bottomed flask equipped with a thermocouple, condenser, and a magnetic stirrer, under nitrogen purge in an oil bath at $120{ }^{\circ} \mathrm{C}$ for 16 hours to complete polymerization reaction. Finally, the obtained PCL diol was precipitated in n-hexane and dried under vacuum at $50{ }^{\circ} \mathrm{C}$.

2.2.2. Synthesis of Polyurethane (PCL-PU- $\beta C D$ ).

PCL-PU- $\beta C D$ was synthesized by reacting $6 \mathrm{~g}$ of dried PCL diol, $1.1 \mathrm{~g}$ of HDI, and one drop of stannous octoate in a $250-\mathrm{mL}$ three-necked round-bottomed flask equipped with a thermocouple, condenser, and a magnetic stirrer and heated at $80{ }^{\circ} \mathrm{C}$. After 3 hours, $3.4 \mathrm{~g}$ of $\beta C D$ dissolved in $30 \mathrm{~mL} \mathrm{DMF}$ and two drops of stannous octoate were added to the reacting mixture. This mixture was stirred at $80{ }^{\circ} \mathrm{C}$ for 20 hours. Then the product was poured into a large amount of deionized water several times then washed with methanol to remove unreacted $\beta C D$ and excess of catalyst. The product was then dried in a vacuum oven at $50{ }^{\circ} \mathrm{C}$.

2.2.3. Synthesis of C5-curcuminoids; [(1E,4E)-1,5-di(phenyl)penta1,4-dien-3-one(PhPO) and (1E,4E)-1,5-di(thiophen-2-yl)penta1,4-dien-3-one (ThPO)].

$\mathrm{PhPO}$ and ThPO were synthesized by the Aldol condensation of benzaldehyde or thiophene-2-carbaldyde with acetone under basic conditions using $\mathrm{NaOH}$ as a catalyst.

2.3. Characterization of PCL diol, PCL-PU- $\beta C D$, and synthesized C5-curcuminoids.

2.3.1. Fourier transforms infrared spectroscopy (FTIR).

FTIR spectra of samples were recorded on an FTIR 8400 SHIMADZU between 4000 and $600 \mathrm{~cm}-1$.

\subsubsection{Nuclear magnetic resonance (NMR).}

The $1 \mathrm{H}$ spectra samples were recorded on a Bruker spectrometer Spectrospin $400 \mathrm{MHz}$. Chemical shifts are given in ppm relative to Tetramethylsilane (TMS) as an internal reference.

2.3.3. Thermogravimetric analysis (TGA).

TGA was carried out with a thermobalance (SDTQ 600 thermogravimetric analyzer) using a platinum crucible. The sample $(5.0 \pm 0.1 \mathrm{mg})$ was heated from 20 to $700{ }^{\circ} \mathrm{C}$ at a heating rate of $10{ }^{\circ} \mathrm{C} \mathrm{min}-1$ under an air purge of $100 \mathrm{~mL} / \mathrm{min}$. 


\subsection{Estimation of the Standard Curves.}

\subsubsection{Estimation of the Standard Curve for ThPO drug.}

Specific concentrations of ThPO drug in $10 \%$ ethanolic phosphate buffer ( $\mathrm{pH}$ 7.4) solutions were scanned spectrophotometrically (Agilent Technologies, Cary series UV-vis spectrophotometer, California, USA) between 200 and $800 \mathrm{~nm}$ in order to determine the wavelength of maximum absorbance $(\lambda \max )$. The standard curve for ThPO at $\mathrm{pH} 7.4$ was plotted at the assessed $\lambda \max$ for a series of ThPO dilutions containing different drug concentrations.

\subsubsection{Estimation of the Standard Curve for Curcumin (Cur) drug.}

Specific concentrations of Cur drug in $10 \%$ ethanolic phosphate buffer ( $\mathrm{pH} 7.4)$ solutions were scanned spectrophotometrically (Agilent Technologies, Cary series UV-vis spectrophotometer, California, USA) between 200 and $800 \mathrm{~nm}$ in order to determine the wavelength of maximum absorbance ( $\lambda \max$ ). The standard curve for Cur at $\mathrm{pH} 7.4$ was plotted at the assessed $\lambda \max$ for a series of Cur dilutions containing different drug concentrations.

\subsubsection{Estimation of the Standard Curve for PhPO drug.}

Specific concentrations of $\mathrm{PhPO}$ drug in $10 \%$ ethanolic phosphate buffer ( $\mathrm{pH} 7.4)$ solutions were scanned spectrophotometrically (Agilent Technologies, Cary series UV-vis spectrophotometer, California, USA) between 200 and $800 \mathrm{~nm}$ in order to determine the wavelength of maximum absorbance ( $\lambda$ max). The standard curve for $\mathrm{PhPO}$ at $\mathrm{pH} 7.4$ was plotted at the assessed $\lambda \max$ for a series of $\mathrm{PhPO}$ dilutions containing different drug concentrations.

\subsection{Preparation of Curcuminoids-loaded PCL-PU- $\beta C D$ nanocomposites.}

\subsubsection{First preparation technique.}

Preparation of such Curcuminoids-loaded nanocomposites (formulae M 4, M 5, M 7 relative to $\mathrm{PhPO}$, ThPO, and Cur drugs, respectively) was carried out using the emulsion solvent adaptation technique [52-54] with some modifications. 0.1gm of the PCL-PU- $\beta C D$ polymer was dissolved in $1 \mathrm{~mL}$ DMSO. Then the drug was added (10mg of the ThPO, Cur, and $\mathrm{PhPO}$ drugs individually) to this polymer solution and stirred till the drug was totally disappeared, next to both of; $5 \%$ of Tween 80 and $0.2 \mathrm{gm}$ of Pluronic F68 were added to the previously made aqueous solution and completed with double distilled water to $10 \mathrm{~mL}$. Finally, such polymeric aqueous solution was sonicated for an hour.

\subsubsection{Second preparation technique.}

In this technique, a new modified combined polymer prepared the Curcuminoidsloaded nanocomposites (formulae M 1, M 3, M B relative to ThPO, Cur, and PhPO drugs, respectively) emulsification technique [55-57] as the preparation included two portions. In portion "A", a certain amount of the PCL-PU- $\beta C D$ polymer is calculated relative to the polymer and drug molecular weights and equivalent to a specific quantity of the drug (the amounts of the same drug used in the previous technique), was dissolved in $1 \mathrm{~mL}$ DMSO. Where both the drug and polymer solution were added to $1.6 \mathrm{~mL}$ of oleic acid and sonicated for 5-10 mins at 
$60^{\circ} \mathrm{C}$ till a homogenous system is obtained with no traces of the drug or the polymer, and then $0.6 \mathrm{~mL}$ ethanol is added and mixed by stirring gently. In portion "B", $4 \mathrm{~mL}$ double distilled water is mixed with $1.8 \mathrm{~mL}$ Tween 80 by using the vortex (Vortex VELP SCIENTIFICA, Europe). Finally, portion "B" is added drop-wise to portion "A" with homogenization for 10 mins at $15,000 \mathrm{rpm}$.

\subsection{Entrapment efficiency investigation.}

Nanocomposites with a known drug concentration were properly dissolved and diluted with ethanolic phosphate buffer ( $\mathrm{pH} 7.4$ ) and then centrifuged at 10,000 rpm for 10-15 min (Heraeus Centrifuges, Thermo Fisher Scientific, Germany) in order to separate the free drug. The drugs concentrations were measured spectrophotometrically each at its specific wavelength, and their entrapment efficiency percentages (E.E \%) were determined using the following equation (1): [58]

$$
\text { Entrapment Efficiency }=\frac{\text { Initial weight of drug-weight of drug in supernatant }}{\text { Initial weight of drug }} \times 100
$$

\subsection{Release study.}

\subsubsection{In-vitro drug release experiment.}

Such release experiment was fulfilled by placing one milliliter of the prepared Curcuminoids-loaded nanocomposites containing a certainly known drug concentration in a dialysis bag membrane with a molecular weight Cut-Off $(12,000 \mathrm{~g} / \mathrm{mol})$, tied with a dialysis

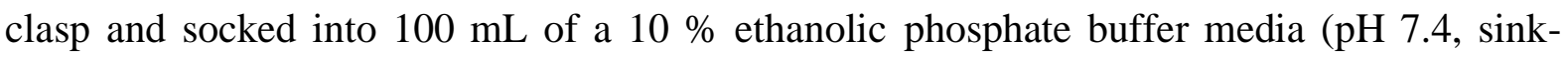
condition). Each sample was made in a triplicate (three times). The entire system samples were incubated at $37 \pm 0.5^{\circ} \mathrm{C}$ in a shaking water bath (Daihan-brand Digital Precise Shaking Water Bath, Daihan Scientific Co., Thailand) operated with a stirring speed of $50 \mathrm{rpm}$. At selected time intervals of $1,2,3,4,6,8,24,48,72,96,192,240$, and 336 hours, $2 \mathrm{~mL}$ aliquots were withdrawn from the release medium and replaced with a similar quantity of fresh buffermedium to determine the absorbance spectrophotometrically for each drug at its specific wavelength. To check for any possible limiting effects of the used membrane on the drug release, a separate experiment was run with free drugs solution under the same conditions.

\subsubsection{Drug release kinetics.}

In order to bear the best depiction for the drug-releasing from the prepared Curcuminoids-loaded nanocomposites and also to adequately determine their release profiles, the data of in-vitro drug release from drug-loaded nanocomposites was fitted to five primarily applied mathematical models, namely; zero-order, first-order, second-order, Higuchi matrix and Korsmeyer-Peppas model.

$$
\text { Zero-order: } \mathrm{M}=k_{0} \mathrm{t}
$$

$$
\text { First-order: } \log \mathrm{M}=\log \mathrm{M}_{0}-k_{1} \mathrm{t} / 2.303
$$

Second-order: $\frac{1}{\mathrm{M}_{0-M}}=\frac{1}{\mathrm{M}_{0}}-\mathrm{k}_{2} \mathrm{t}$

Higuichi model: $M=k_{H} t^{1 / 2}$ 
Korsmeyer-Peppas model: $\log \left(\frac{M}{M \infty}\right)=\log k_{k-p}+n \log t$

Where M0 is the initial concentration of drug; $\mathrm{M}$ is the amount released at time $\mathrm{t} ; \mathrm{M} \infty$ is the amount of the drug released after an infinitive time (in this research after 336 hours), and the $\mathrm{k} 0, \mathrm{k} 1, \mathrm{k} 2, \mathrm{kH}$ and $k_{k-p}$ represent zero-order release constant, the first-order release constant, Second-order release constant, Higuchi constant, and Korsmeyer-Peppas constant, respectively.

The model with the highest correlation coefficient values or determination coefficient (R2) was considered to be the best fit model [59-62].

\subsubsection{Mechanism of drug release.}

To find out the mechanism of drug release, the release exponent (n) describing the mechanism of drug release from the matrices was calculated by regression analysis using the following equation:

$$
\mathrm{Mt} / \mathrm{M} \infty=\mathrm{ktn}
$$

Where $\mathrm{Mt} / \mathrm{M} \infty$ is the fraction of drug released at time $\mathrm{t}$ and $\mathrm{k}$ is a constant incorporating the structural and geometric characteristics of the release device. To realize the release kinetic mechanisms of such nanocomposites, data obtained from in vitro drug release studies were plotted as log cumulative percentage drug release versus log time. In this model, the value of $n$ characterizes the release mechanism of the drug. As, when the value of $n \leq 0$. 5, Case I or Fickian mechanism diffusion is indicated, $0.5<\mathrm{n}<1$ for anomalous (non-Fickian) diffusion, $\mathrm{n}=1$ for Case II (relaxational) transport (Zero-order release), and $\mathrm{n}>1$ indicates Super case II transport [63].

\subsection{Characterization of nanocomposites.}

\subsubsection{Transmission Electron Microscope Study.}

A High-Resolution Transmission Electron Microscope (JEOL JEM 2100 T.E.M. HR, Japan) was used to evaluate the particle shape and size of the Curcuminoids-loaded nanocomposites; the particle size was measured using the NIH image software. The nanocomposites suspensions were stained with phosphotungstic acid dye, then sprayed on a Formwar-coated copper grid, and air-dried before observation.

\subsubsection{Particle size analyses of the nanocomposites.}

Particle size and polydispersity index of the Curcuminoids-loaded nanocomposites were measured by Dynamic Light Scattering instrument (PSS, Santa Barbara, CA, USA). The samples were suitably diluted before undergoing the measurements. The analysis was carried out at room temperature $\left(25{ }^{\circ} \mathrm{C}\right)$, using the $632 \mathrm{~nm}$ line of a HeNe laser as the incident light with angel $90^{\circ}$.

\subsubsection{Studying FT-IR analyses of the nanocomposites.}

The FT-IR spectral measurements were taken at ambient temperature using FT-IR spectrophotometer (FT-IR, Shimadzu $8400 \mathrm{~S}$, Japan), implying $\mathrm{KBr}$ pellet method to understand if some interaction between drugs and nanocomposites existed. The procedure consisted of mixing the sample with $\mathrm{KBr}$, then placing such mixture into the sampling cup. 
The sample was positioned in the light path, and the spectrum was obtained. Individual components of ThPO, PhPO, Cur, and PCL-PU- $\beta C D$ were run as controls. The scanning range was kept from 4,000 to $400 \mathrm{~cm}-1$, and the resolution was $16 \mathrm{~cm}-1$.

\subsubsection{Scanning Electron Microscope study.}

The surfaces of Curcuminoids-loaded nanocomposites were examined using a scanning electron microscope (Quanta FEG 250, JAPAN). Samples were deposited on a glass slide and were kept under a vacuum. The samples were coated with a thin gold/palladium layer using a sputter coater unit. The scanning electron microscope was operated at an acceleration voltage of $15 \mathrm{kV}$.

2.8.5. Thermogravimetric analysis (TGA) of the nanocomposites.

TGA was carried out with a thermobalance (SDTQ 600 thermogravimetric analyzer) using a platinum crucible. The sample $(5.0 \pm 0.1 \mathrm{mg})$ was heated from 20 to $700{ }^{\circ} \mathrm{C}$ at a heating rate of $10{ }^{\circ} \mathrm{C}$ min- 1 under an air purge of $100 \mathrm{~mL} / \mathrm{min}$.

2.9. Estimation of in-vitro cell viability and cytotoxicity of Curcuminoids-loaded nanocomposites on normal cells.

\subsubsection{Cell culture.}

An MCF-7 human breast cancer cell line (VACSERA, Egypt) was cultured in an RPMI1640 medium (Gibco, Invitrogen, Carlsbad, CA) supplemented with $10 \%$ heatinactivated fetal bovine serum (FBS) (Gibco, Invitrogen), $2 \mathrm{~g} / \mathrm{mL}$ sodium bicarbonate, 80 $\mathrm{mg} / \mathrm{mL}$ penicillin $\mathrm{G}$ (Serva, Germany), $50 \mathrm{mg} / \mathrm{mL}$ streptomycin (Merck, Germany), and incubated at $37^{\circ} \mathrm{C}$ with humidified air containing $5 \% \mathrm{CO} 2$.

2.9.2. In-vitro Cell Viability and MTT-based cytotoxicity assay of Curcuminoids-loaded Nanocomposites

After culturing a sufficient amount of MCF-7 human breast carcinoma cells and normal Vero epithelial cells (VACSERA, Egypt), the cytotoxic effects of synthesized Curcuminoidsloaded nanocomposites were studied using MTT assays. Briefly, 10000 cells/well were cultivated in a 96-well plate (Costar from Corning, NY). After 24 hours of incubation at $37^{\circ} \mathrm{C}$ in a humidified atmosphere, including 5\% $\mathrm{CO} 2$, the cells were treated with serial concentrations of Curcuminoids-loaded nanocomposites $(0.5-70 \mathrm{mM})$ for 24 hours replicated four times. The control test was prepared by treating the cells with $0 \mathrm{mg} / \mathrm{mL}$ of the nanocomposities and $200 \mathrm{~mL}$ of the culture medium containing 10\% DMSO. After incubation, the medium in all wells of the plate was substituted with a fresh medium and then incubated for another 24 hours. Then the wells media were removed carefully, followed by adding fifty milliliters of MTT (2 mg/mL; Sigma Co., Germany) dissolved in phosphate-buffered solution to each well, and the plate was covered with aluminum foil and incubated for 4 hours. Next, $200 \mathrm{~mL}$ of pure DMSO was added to the wells after eliminating the contents of the wells. Next, $25 \mathrm{~mL}$ of Sorensen's glycine buffer was added, and the absorbance of each well was instantly read at $560 \mathrm{~nm}$ using an EL×800 microplate absorbance reader (Bio Tek Instruments, Winooski, VT) with a reference wavelength of $620 \mathrm{~nm}$. 
All results: were represented as mean $\pm S D$, Standard Deviation $(n=3)$. The analysis for the comparison of group variations was done by (ANOVA) followed by; LSD-test. Differences were reported significant when ( $\mathrm{p}$ is lower than 0.05 ).

\section{Results and Discussion}

\subsection{Synthesis and characterization of PCL pre-polymer and PCL-PU- $\beta C D$.}

The polymer was synthesized in a two-step reaction. As shown in Figure 1, PCL-diol pre-polymer was synthesized by stannous octoate catalyzed ring-opening polymerization of $\varepsilon$ caprolactone in the presence of 1,4-butandiol. PCL-PU- $\beta C D$ was prepared by the reaction of PCL-diol with hexamethylene diisocyanate (HDI) and $\beta C D$ as chain extender, respectively. FTIR spectroscopy and 1HNMR data indicated that the reaction had been completed. FTIR spectra of PCL-PU- $\beta C D$ showed distinct peaks at $1725 \mathrm{~cm}-1$ assigned for the urethane $\mathrm{C}=\mathrm{O}$ band and at $1633 \mathrm{~cm}-1$ peak for the urethane $\mathrm{NH}$ bending (Figure 2i). The strong, broad peak at $3432 \mathrm{~cm}^{-1}$ is due to free and hydrogen-bonded urethane $\mathrm{N}-\mathrm{H}$ stretching and $-\mathrm{OH}$ stretching of $\beta C D$ present in PCL-PU- $\beta C D$. Moreover, the absence of isocyanate (-NCO) absorption at $2270 \mathrm{~cm}-1$ confirmed the completion of the reaction.

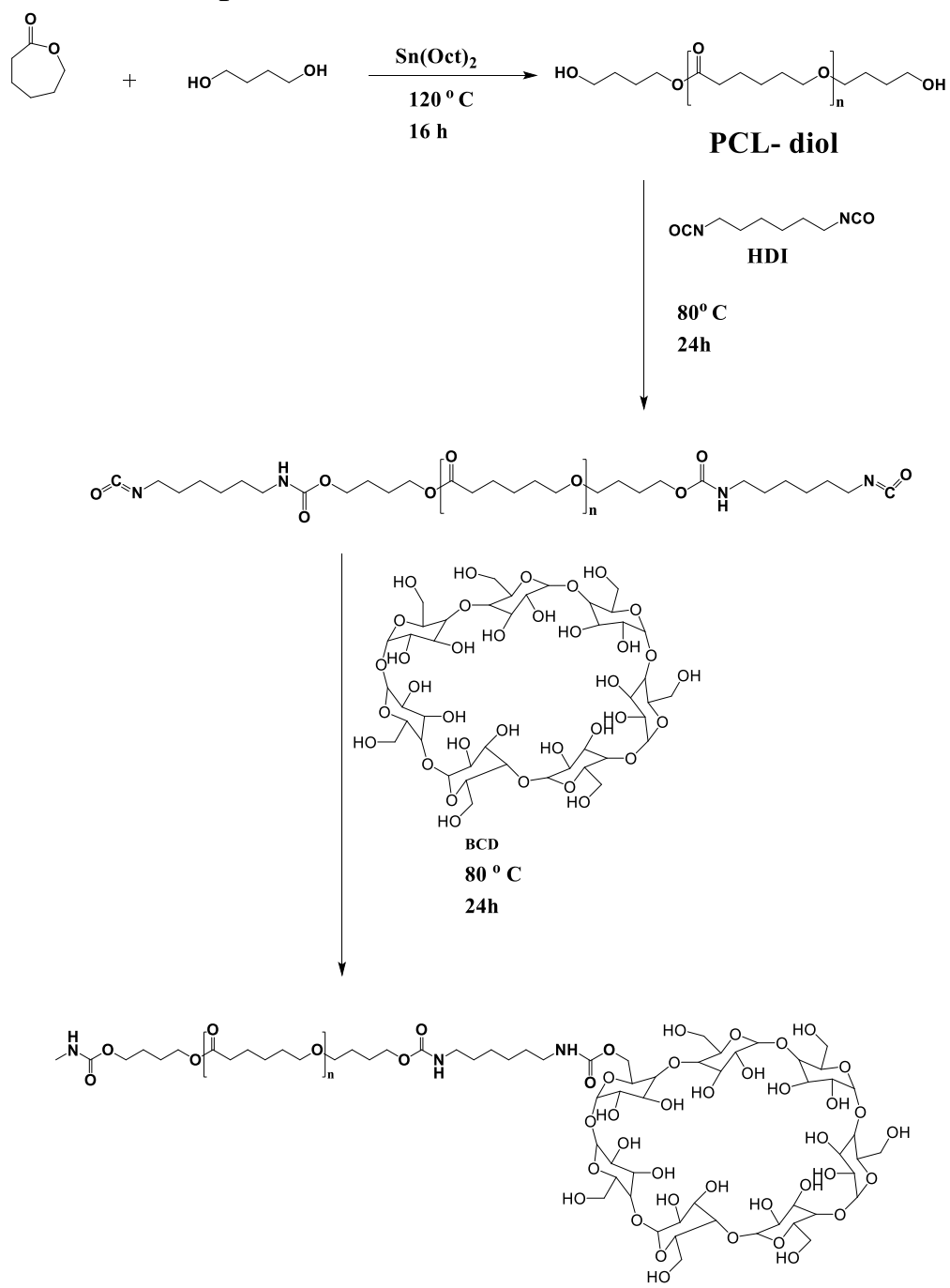

Figure 1. Synthetic scheme of the newly synthesized PCL-PU- $\beta C D$ polymer.

1H-NMR (400 MHz, DMSO) spectra of PCL-PU- $\beta C D$ was shown in Figure 2ii. The peaks of (a') were assigned to the methylene protons $(-\mathrm{CH} 2-\mathrm{CH} 2-\mathrm{CH} 2)$ at $\delta=1.39 \mathrm{ppm}$ and ($\mathrm{CH} 2-\mathrm{CH} 2-\mathrm{O}$ ) at $\delta=1.63 \mathrm{ppm}$. The (b') peaks at $\delta=2.28 \mathrm{ppm}$ were assigned to the methylene 
protons $(-\mathrm{CH} 2 \mathrm{COO})$. The peak at $\delta=2.92 \mathrm{ppm}$ was due to $\mathrm{H} 4$ protons $[-\mathrm{CH}(\mathrm{OH})]$ of $\mathrm{C} 4$ for $\beta C D$. The intense peak at $\delta=3.33-3.37$ ppm was due to protons $(-\mathrm{CH} 2-\mathrm{CH} 2-\mathrm{O})$ of PCL unites, (c') methylene protons $(-\mathrm{CH} 2-\mathrm{NH})$, and $\mathrm{H} 2$ protons $[-\mathrm{CH}(\mathrm{OH})]$ of $\mathrm{C} 2$ for $\beta C D$. The peak at $\delta=3.52 \mathrm{ppm}$ was due to $\mathrm{H} 5$ protons $[-\mathrm{CH}(\mathrm{OH})]$ of $\mathrm{C} 5$ for $\beta \mathrm{CD}$. The peaks at $\delta=3.95-4.03 \mathrm{ppm}$ were due to (e') methylene protons $(-\mathrm{CH} 2 \mathrm{OCO})$ and $\mathrm{H} 6, \mathrm{H} 3$ protons $[-\mathrm{CH}(\mathrm{OH})]$ of $\mathrm{C} 6$ and $\mathrm{C} 3$ for $\beta \mathrm{CD}$. The peaks at $4.28,4.5$, and $4.88 \mathrm{ppm}$ were due to $\mathrm{H} 6 *$, OH6, and $\mathrm{H} 1$ protons [$\mathrm{CH}(\mathrm{OH})]$ of * $\mathrm{C} 6, \mathrm{C} 6$, and $\mathrm{C} 1$ for $\beta \mathrm{CD}$, respectively. The peaks at 5.65-5.80 ppm were due to $\mathrm{OH} 2, \mathrm{OH} 3$ protons $[-\mathrm{CH}(\mathrm{OH})]$ of $\mathrm{C} 2$ and $\mathrm{C} 3$ for $\beta \mathrm{CD}$. The appearance of a new signal (f') at $\delta=7.0 \mathrm{ppm}$ indicated the $\mathrm{NH}$ proton in $(-\mathrm{CO}-\mathrm{NH})$ urethane linkage [64].

i

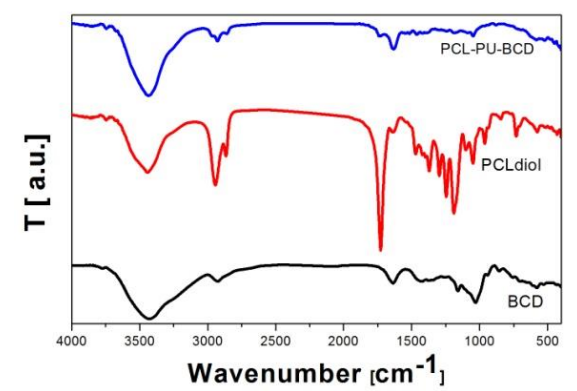

ii

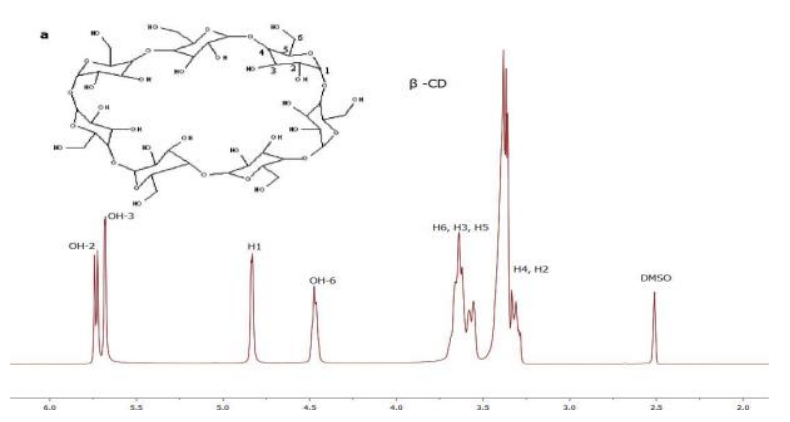

b
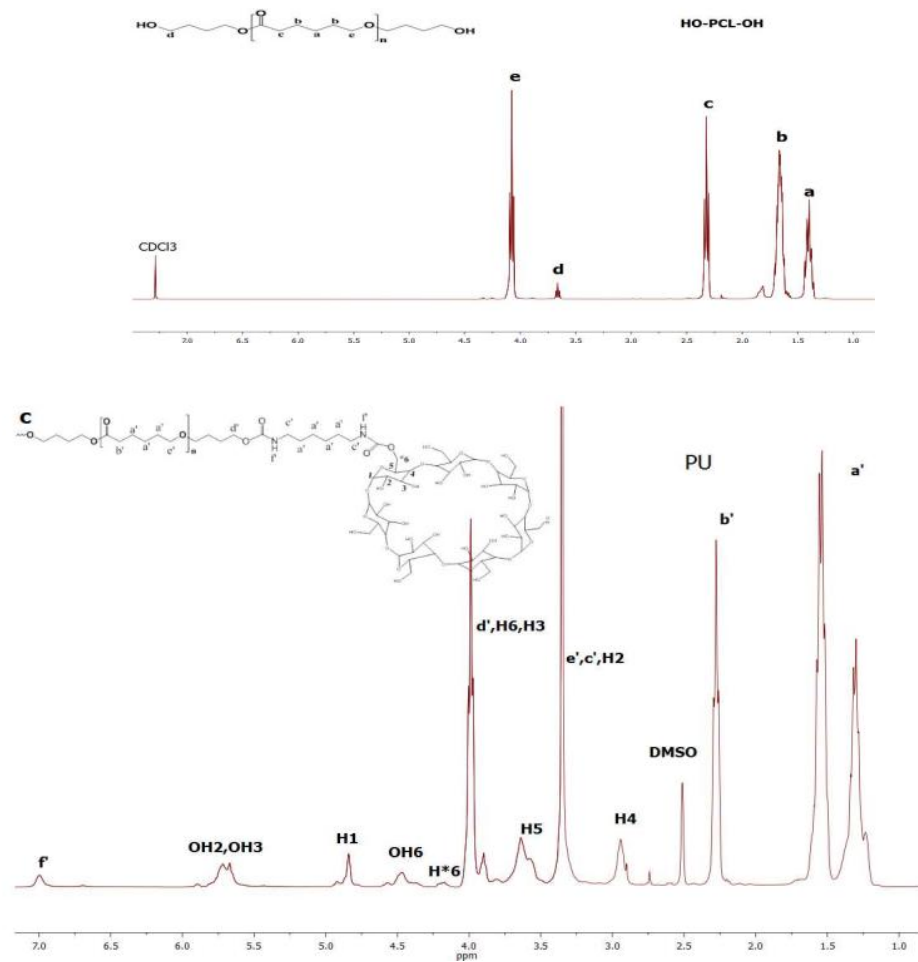

Figure 2. (i) FT-IR spectrum patterns of PCLdiol, $\beta C D$, and the newly synthesized PCL-PU- $\beta C D$ polymer; (ii) $1 \mathrm{H}$ NMR spectra of; (a) $\beta C D$; (b) synthesis PCL-diol; (c) the newly synthesized PCL-PU- $\beta C D$ polymer. 


\subsection{Synthesis and characterization of the synthesized C5-curcuminoidal drugs.}

The ThPO, PhPO drugs were synthesized according to the schematic reaction shown in Figure3i. As shown in Figure 3ii, the FT-IR spectrum curves of Curcuminoidal drugs (Cur, ThPO, and PhPO) manifested a wide peak at $3500-3300 \mathrm{~cm}^{-1}$ plus a sharp explicit peak at $3430 \mathrm{~cm}-1$ for the raw Cur drug especially, expressing the phenolic O-H stretching. Sharp, distinct absorption signals at 1628 and $1605 \mathrm{~cm}^{-1}$, were related to $\mathrm{C}=\mathrm{C}$ in all the Curcuminoidal drugs. Besides another strong, unique band at $1598 \mathrm{~cm}-1$ that was correspondent to the benzene rings stretching of both Cur and PhPO drugs, a specific peak of the ThPO drug at $3067 \mathrm{~cm}^{-1}$ referred to the $\mathrm{C}-\mathrm{H}$ stretching of the ThPO ring. The raw Cur specific peak at $1507 \mathrm{~cm}^{-1}$, pertained to the carbonyl groups $\mathrm{C}=\mathrm{O}$ vibration, while the enol $-\mathrm{C}-\mathrm{O}$ peaks were indicated at 1278 and $1269 \mathrm{~cm}-1$. Distinguished absorption bands at 1028 and $858 \mathrm{~cm}^{-1}$, represented the C$\mathrm{O}-\mathrm{C}$ stretching of the raw Cur drug, in addition to the obvious signals at 1036 and $863 \mathrm{~cm}-1$, that could be referred to as the $\mathrm{C}=\mathrm{O}$ of the ThPO drug, similarly to the $\mathrm{PhPO}$ drug characteristic bands at 1028 and $857 \mathrm{~cm}^{-1}$.

1H-NMR (400 MHz, CDCl3) spectrum of ThPO was shown in Figure 3iii. The peaks that appeared at $\delta=6.75 \mathrm{ppm}$ and $7.32 \mathrm{ppm}$ were assigned to $\mathrm{H} 1$ and $\mathrm{H} 4$ protons $(-\mathrm{CH}=\mathrm{CH}-$ $\mathrm{C}=\mathrm{O}$ ) of the aliphatic chain, respectively. The aromatic thiophene protons $\mathrm{H} 2, \mathrm{H} 3$, and $\mathrm{H} 5$, appeared at $\delta=6.99,7.25$, and $7.77 \mathrm{ppm}$, respectively. It is well known that the chemical shift of $\mathrm{PhPO}$ protons resonate in the range of 7.08-7.77 ppm [65].

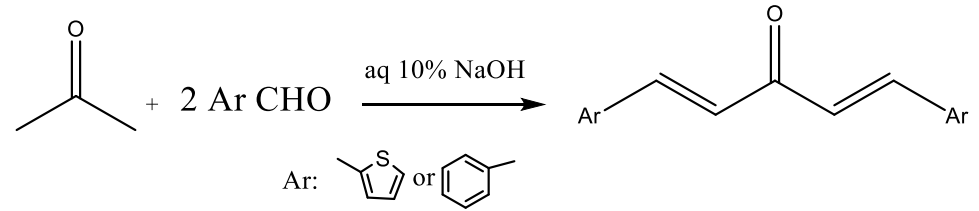

ii

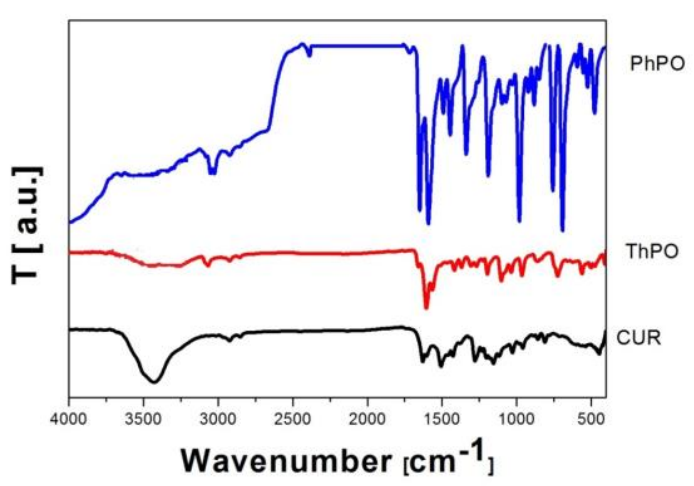

iii

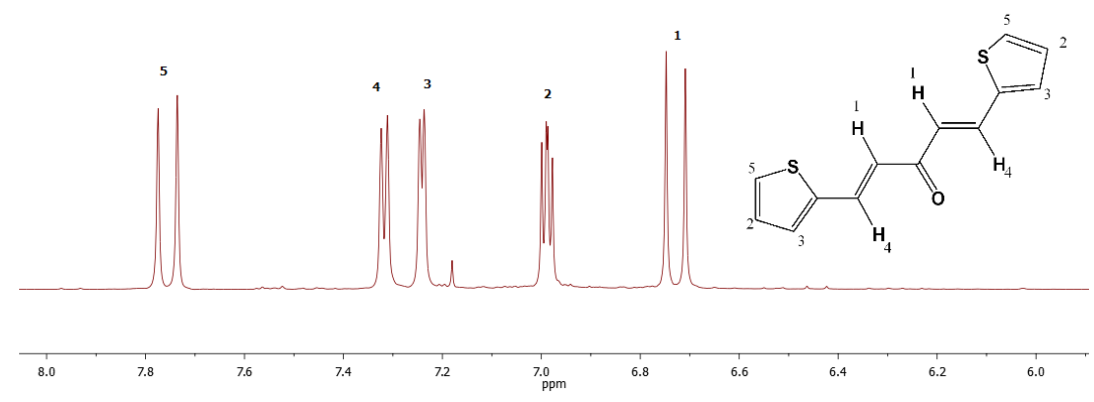


iv
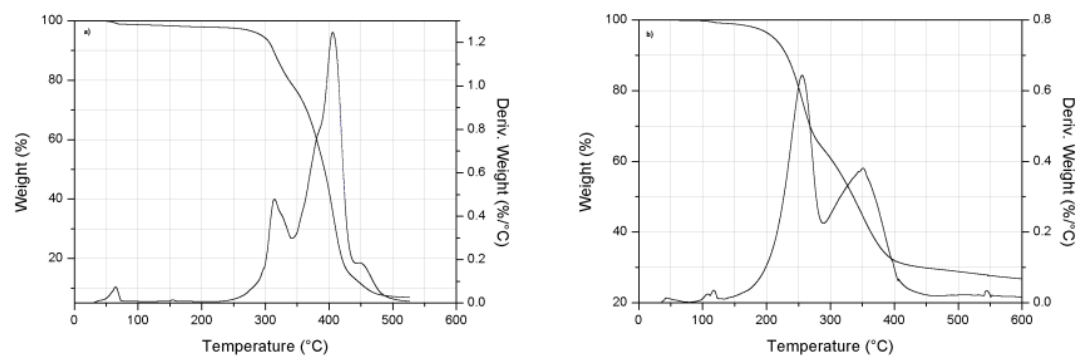

Figure 3. (i) Illustration of the synthesis of newly synthesized ThPO, PhPO drugs; (ii) FT-IR spectrum patterns of Cur and the newly synthesized ThPO, PhPO drugs; (iii) ${ }^{1} \mathrm{H}$ NMR spectrum of the newly synthesized ThPO drug; (iv) TGA and DTG curves of the newly synthesized; (a) PCL-PU- $\beta C D$; (b) ThPO drug.

\subsection{Thermal stability analysis of the PCL-PU- $\beta C D$ and synthesized C5-curcuminoid drug} (ThPO).

The thermal stability for PCL-PU- $\beta C D$ and synthesized C5-curcuminoid drug (ThPO) was investigated. Figure 3iv, showed the thermogravimetric (TGA) and derivative thermogravimetric (DTG) curves of three compounds. The PCL-PU- $\beta C D$ revealed degradation in two stages. The first stage at $263{ }^{\circ} \mathrm{C}-342{ }^{\circ} \mathrm{C}$ was attributed to urethane bondbreaking resulting in de-polymerization to hard and soft segments [66,67] and decomposition of $\beta C D$ [68]. The second stage at $\left(343{ }^{\circ} \mathrm{C}-490{ }^{\circ} \mathrm{C}\right)$ was attributed to the decomposition of PCL segments [66,69].

The decomposition of the synthesized C5-curcuminoid drug (ThPO) was taken place also in two steps at $\left(196{ }^{\circ} \mathrm{C}-292^{\circ} \mathrm{C}\right)$ and $\left(292{ }^{\circ} \mathrm{C}-430^{\circ} \mathrm{C}\right)$ and showed a similar thermal decomposition of curcumin (Cur) that was occurred in two stages starting at $\left(215^{\circ} \mathrm{C}-354{ }^{\circ} \mathrm{C}\right.$ ), and $\left(215^{\circ} \mathrm{C}-469^{\circ} \mathrm{C}\right)[70,71]$.

\subsection{Estimation of the standard curves for Curcuminoidal drugs.}

The spectrophotometric scanning of this study Curcuminoidal drugs (Cur, ThPO, and $\mathrm{PhPO}$ ) revealed that the wavelength relative to the maximum absorbance in $10 \%$ ethanolic phosphate buffer ( $\mathrm{pH}$ 7.4) for each of; Cur-drug, ThPO-drug, and PhPO-drug was realized to be at 420, 388, and $319 \mathrm{~nm}$, respectively. The standard curves of all the Curcuminoidal drugs manifested typical linearity representing the relationship between the various drugs' serial dilution concentrations and their corresponding absorbance values at 420, 388, and $319 \mathrm{~nm}$, individually for Cur, ThPO, and PhPO drugs, respectively (Figure 4i). This reflected the obviously aloft linearity of such standard curves coefficient values (R2) that were distinguished to be almost $\approx 1$ as shown in Figure 4 .

\subsection{Entrapment efficiency.}

Entrapment efficiency is one of the remarkable parameters to promote the leverage of anti-cancer drugs in order to prove these drugs' clinical usage. Entrapment efficiency percentages of Curcuminoids-loaded nanocomposites shown in Table 1, were conspicuously favorable and ranging from $99.51 \pm 1.20$ to $98.66 \pm 0.17 \%$. As the amphiphilic PCL-PU- $\beta C D$ copolymers forming such nanocomposites consisted of hydrophobic PCL-moieties and hydrophilic $\beta$-CD terminals, with the ability to absorb or entrap specific quantities of the 
Curcuminoidal drugs $[72,73]$. The elevated Curcuminoids-loading within the nanocomposites could be first referred to as the perfect hydrophobicity of PCL-segments, permitting such segments hydrophobic interactions that could promote the formation of cores and providing an adequate reservoir for loading drug molecules [72]; along secondly with the interactions between the hydrophilic branches of $\beta-\mathrm{CD}$ and the water, leading to the fine protection of the encapsulated molecules in addition to the competent stabilization of nanocomposites [73,74], beside $\beta$-CD hydrophobic internal cavities that $[9,12,13]$, can valuably encourage the enclosing of more drug molecules.

Table 1. Percentage of entrapment efficiency (E.E.\%), polydispersity index (P.I.), and average particle size (A.P.S.) of the prepared and selected nanocomposite formulations.

\begin{tabular}{l|l|l|l} 
Formula & E.E.\%* & A.P.S. $(\mathbf{n m})$ & P.I.* \\
\hline M 1 & $99.51 \pm 1.20$ & 131.46 & $0.542 \pm 0.18$ \\
\hline M 3 & $99.22 \pm 1.30$ & 98.82 & $0.568 \pm 0.40$ \\
\hline M 4 & $99.08 \pm 2.50$ & 38.67 & $0.259 \pm 2.50$ \\
\hline M 5 & $99.33 \pm 0.60$ & 42.45 & $0.443 \pm 1.60$ \\
\hline M 7 & $98.66 \pm 0.17$ & 40.35 & $0.533 \pm 0.90$ \\
\hline M B & $99.14 \pm 0.40$ & 86.61 & $0.596 \pm 0.27$ \\
* Data are expressed as Mean \pm SD, $n=3$.
\end{tabular}

From Table 1, it was clearly identified that formulae prepared with the second technique; M 1, M 3, and M B attained a slightly higher entrapment percentage range (99.51 \pm $1.20-99.14 \pm 0.40 \%)$ relatively to the entrapment percentage range $(99.33 \pm 0.60-98.66 \pm$ $0.17 \%$ ) of formulae prepared with the first technique; M 4, M 5, and M 7, which can be explained due to the narrowly higher polymer concentrations that were used in the preparation of formulae M 1, M 3, and M B in contrast to formulae M 4, M 5, and M 7. As, increasing the polymer concentration resulted in an increase in the drug atoms' diffusional resistance, causing retaining of more drug quantities within the polymeric particles, leading to increasing the polymer content of the drugs yielding higher entrapment efficiencies [75]. Besides the effect of the presence of oleic acid within M 1, M 3, and M B (nano-formulations prepared with the second technique) in elevating their entrapment capacity due to their higher hydrophobic interaction zones, that was similarly documented by Dhillon, Sharma, Jain, Sharma, and Arora [76]. In contrast, other literature attested that nano-formulae containing Pluronic F68, as M 4, M 5, and M 7 in this survey, showed lower entrapment efficiencies that could be related to the low hydrophobic - $\mathrm{CH} 3$ - groups in the Pluronic F68 copolymers leading to lowering their hydrophobic interaction-sites between the drug and their micellar cores and thus minimizing the solubilization of hydrophobic drug molecules [77]. Even though these samples, M 4, M 5, and M 7, contained Pluronic F68, their lower entrapment efficiencies were not significantly different ( $\mathrm{p}$ higher than 0.05 ) to those samples, M 1, M 3, and M B, containing oleic acid.

Table 2. The release kinetics profiles of the Curcuminoids-loaded nanocomposite formulae.

\begin{tabular}{|c|c|c|c|c|c|c|c|c|c|c|c|}
\hline \multirow[t]{2}{*}{ Formulae } & \multicolumn{2}{|c|}{ Zero-Order } & \multicolumn{2}{|c|}{ First-Order } & \multicolumn{2}{|c|}{ Second-Order } & \multicolumn{2}{|c|}{ Higuchi Model } & \multicolumn{3}{|c|}{ Peppas model } \\
\hline & $\mathbf{R}^{2}$ & $\mathbf{K}$ & $\mathbf{R}^{2}$ & $\mathbf{K}$ & $\mathbf{R}^{2}$ & K & $\mathbf{R}^{2}$ & K & $\mathbf{R}^{2}$ & K & $\mathbf{n}$ \\
\hline M 1 & 0.6874 & 0.0435 & 0.5506 & 0.0017 & 0.3954 & 0.0004 & 0.8747 & 0.9058 & 0.9615 & 0.2806 & 0.4144 \\
\hline M 3 & 0.8598 & 0.1 & 0.6659 & 0.0 & 0.4461 & 0. & 0.9182 & 61 & 0.9776 & 0.6029 & 0.2859 \\
\hline M 4 & 0.5552 & & 0.4634 & 0.0 & 0.2520 & 0.1 & 0.7 & 5 & 0.9253 & 62 & 71 \\
\hline M 5 & 0.7764 & 0.1045 & 0.5976 & 0.0033 & 0.3902 & 0.0009 & 0.9007 & 2.1111 & 0.9772 & 0.538 & 0.2942 \\
\hline M 7 & 0.8346 & 0.3158 & 0.6473 & 0.0034 & 0.3212 & 0.0003 & 0.9046 & 6.1788 & 0.9586 & 0.5372 & 0.2254 \\
\hline M B & 0.5577 & 0.1560 & 0.4950 & 0.0019 & 0.4281 & 0.0001 & 0.7722 & 3.3879 & 0.9264 & 1.0939 & 0.3283 \\
\hline
\end{tabular}

Chiefly, such high entrapment percentage values led to a beneficial meaning implied that the Curcuminoids-loaded nanocomposites could be considered a suitable carrier for these 
drug delivery, which could be a reason for the fine affinity between such drugs and PCLcopolymers block [78,79].

\subsection{In-vitro release analysis of Curcuminoids-loaded nanocomposite formulations.}

In Figure 4ii, it was obviously noticed that the in-vitro release patterns of the free drugs included a burst effect release for around 6 hours followed by a gradual fast decreasing in the release of the drug, after which the release of the drug is ended, indicating the willingly of the drugs for diffusing freely through the dialysis-membrane. Otherwise, all the Curcuminoidsloaded nanocomposites release patterns exhibited a bi-phasic release (Figure 4ii) phenomenon, with an initial-burst release effect within the first 3 hours followed by a steady, controlled, sustained release state that continued for 366 hours. Within the first release burst phase, it was noticed that samples M 1, M 3, and M B achieved slightly lower burst-effects (ranging between $3.53-6.06 \%$ ) relatively to samples M 4, M 5, and M 7 burst-effects range (3.14 - 10.72\%), such early release stage (almost in the first three hours) was faster than the drug release during the rest 366 hours. This drives to a prediction that the Curcuminoidal drugs are enclosed within the nanocomposite's polymeric cores, and minor amounts of the drugs are associated with the outer surface of these nanocomposites. Making such minor surface drugs amounts, expectedly to directly contact the release medium, causing an instant release of drugs. While, within the second release phase of Curcuminoids-loaded nanocomposites (during the rest 366 hours after the burst-effect period), a slower sustained release manner was obtained Figure 4ii), reflecting that the release of drugs in this phase was dominantly representing drugs enclosed within the nanocomposites. The formulations prepared with the second technique (M 1, M 3, and M B) manifested an ascendant release of the drugs compared to formulations prepared with the first technique (M 4, M 5, and M 7). This could be referred to many reasons; attributed to the higher polymer concentrations in formulations $\mathrm{M} 1, \mathrm{M} 3$, and $\mathrm{M} \mathrm{B}$ in contrast to the other nanocomposites that means a higher number of PCL hydrophobic-esters, causing stronger drug steric hindering by the polymer moieties along with slower hydrolysis of the polymeric esters $[80,81]$ caused by the higher $\beta$-CD hydrophilic branches protection, which by distracting release medium aqueous molecules [74] could cause slowing down their penetration into PCL nanocomposite, and thus could retard the polymeric matrix erosion. The continuous second drug release at 366 hours was deemed to be correlated to the entrapment efficiencies of the nanocomposite formulations.

Generally, this survey agreed with the documentations stating that sustained-release patterns were demonstrated in nanosystems containing oleic acid [76] as in samples M 1, M 3, and $\mathrm{M} \mathrm{B}$, and in nano-polymeric systems containing Pluronic [77], as in samples M 4, M 5, and $\mathrm{M} 7$.

\subsection{Kinetics study of the release data.}

Using in-vitro release data to predict the in-vivo bio-performance is assumed to be a considerable rational development of the controlled drug released nano-formulations [82]. The approaching methods for adequately investigating the drug release kinetic models from the drug-controlled release nanocomposites included using certain mathematical models, involving; zero-order, first-order, second-order, Higuchi-model, and Korsmeyer-Peppas model specifically. As demonstrated in Table 2 and Figure 4iii, it was found that all this study Curcuminoids-loaded nanocomposites obtained the higher regression coefficients (R2) when 
their data of in vitro drug release were fitted into the power law, indicating that the KorsmeyerPeppas mathematical model is the most qualified kinetic model, which competently describes the mechanism of drug release from such nanocomposites. The Curcuminoids-loaded nanocomposites "n" values (Table 2) reflected a Fickian diffusional-controlled release of the drugs.
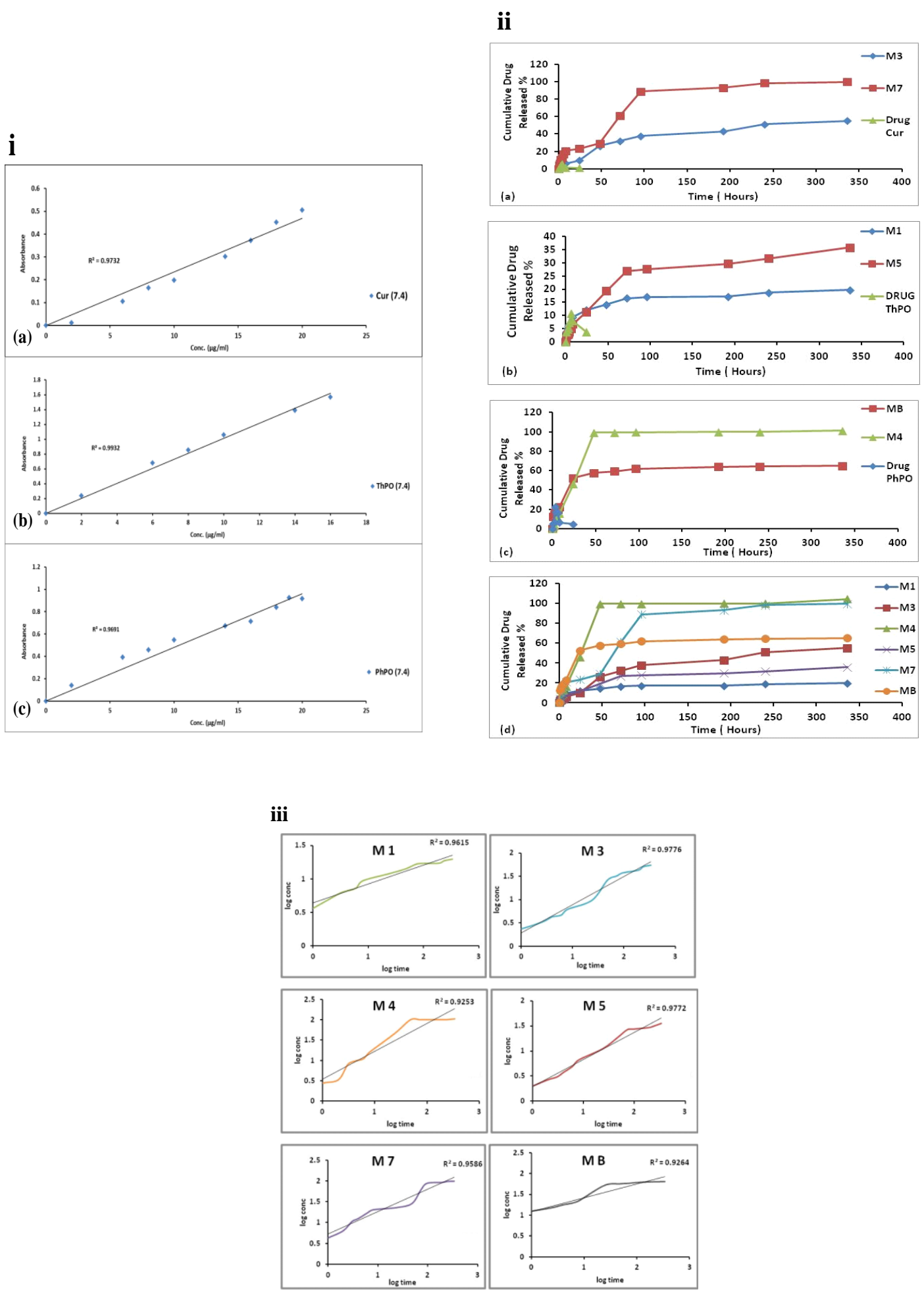

Figure 4. (i) a) Standard curve of Cur in buffer $\mathrm{pH} 7.4$ with $\lambda_{\max }$ of $420 \mathrm{~nm}$, b) Standard curve of ThPO in buffer $\mathrm{pH} 7.4$ with $\lambda_{\max }$ of $388 \mathrm{~nm}, \mathrm{c}$ ) Standard curve of PhPO in buffer $\mathrm{pH} 7.4$ with $\lambda_{\max }$ of $319 \mathrm{~nm}$; (ii) Release profiles of each free drug versus it's nanocomposites; a) Cur, b) ThPO and c) $\mathrm{PhPO}$, and the release profiles of d) all Curcuminoids from the prepared Nanocomposites; (iii) Peppas-model release kinetics profiles of the Curcuminoids-loaded nanocomposite formulae. 
3.8. Characterization of the nanocomposites.

\subsubsection{Transmission Electron Microscopy (TEM).}

The depicted transmission electron microscopy, TEM, images were presented in Figure 5i, showing that PhPO-loaded (M 4, M B) nanocomposites possessed uniformly smart fashioned polygonal micelles together with spherically shaped vesicles. While the Cur-loaded (M 3, M 7) and ThPO-loaded (M 1, M 5) nanocomposites revealed spheroidal ball-shaped micelles and round vesicles. All the Curcuminoids-loaded nanocomposites acquired a reasonable uniformity in the size of their particles, together with smoothly welfare surfaces, reflecting a complete solvent removal from such nanocomposites. All these observations coincide with the TEM spherically shaped dominant morphology results reported in correlation to the preparation techniques $[53,54,56]$.

While for the other new shapes noticed in such study, it fulfills with statements documenting that amphiphilic-block copolymers could construct several interesting morphologies such as globules, fibers, and worms, proving their versatile expediency precursors with supra-molecular shapes [83]. Moreover, amphiphilic PCL-block copolymers could attain different architectures such as micelles and vesicles [73,84-87]. Confirmed by other investigations documenting that, PCL-block copolymers revealed smart micelles with a finely dispersed spheral-globular morphology along with a vesicle-like structure in liquid vehicles [88]. The amphiphilic nature of PCL-block copolymers fructified a vesicle-like structure that included a central wall formed by the PCL segments flanked by the $\beta-C D$, yielding different interfaces of the vesicle. The interfaces nature of vesicle-shaped particles allowed drug adsorption on them, thus providing a long guesting encapsulation of drug molecules, prolonging the drug release [89]. Also, drug release attitude from PCL-Pluronic block co-polymeric micelles implied sustained drug release behaviors [90], which all agree with and explain the outcomes of this study.

\subsubsection{Inspection of the nanocomposites particle sizes.}

As demonstrated in Table 1, both average particle sizes (A.P.S) and polydispersity indexes (P.I) of the Curcuminoids-loaded nanocomposites were analyzed, clarifying that the achieved average particle sizes of formulations prepared with the second technique (M 1, M 3, and $\mathrm{M} \mathrm{B}$ ) ranged between 131.46 and $86.61 \mathrm{~nm}$, while for the formulations prepared with the first technique (M 4, M 5, and M 7), their average particle sizes ranged between 40.35 to 38.67 $\mathrm{nm}$. Several reasons could explicate that; primarily, the higher polymeric concentrations in samples $M$ 1, M 3, and M B, resulting in an increasingly dense sample solution, causing the elevation in the resistance toward the samples formalization breaking down forces of droplets, yielding larger sized particles [91], in the second place, the higher organic-phase quantities used in the formation of such samples, induces the formation of a more viscous sample with a higher reluctance toward the separation-forces during the droplets incorporation, leading to the increment in the particles sizes [92]. Both previously mentioned reasons promoted the increase in the drug-atoms diffusional resistance forces from the organic-phase to the aquatic phase, causing a more detaining of drug-atoms within the polymeric molecules, which proved both the higher entrapment efficiencies and the slower drug diffusion during release, eliciting the prolonged-release demeanor of such samples [75]. On the other hand, the smaller particle sizes acquired by samples M 4, M 5, and M 7, could be referred to the using of a stabilizer along 
with the surfactants within the preparation of these samples, which both increase the formation and stabilization of small-sized particles with a successful avoiding of aggregates consistency [75], likely no phase separations occurred. Besides that reported in different documentations that polymeric nanosystems, specifically including the Pluronic F68 in their preparation, commonly yielded very small-sized particles [93].

In general, the Curcuminoids-loaded nanocomposites attained a decent small nanosized particle not exceeding $150 \mathrm{~nm}$, which could be imputed to the presence of the PCL-block copolymer that was known to exhibit particles with diameters of around $100 \mathrm{~nm}$ [88]. Also, it was documented that amphiphilic block micellar copolymers principally possessed nano-sized particles, which was one of the explanations for their controlled drug release behavior $[89,90]$. Moreover, the Curcuminoids-loaded nanocomposites revealed to own low polydispersity indexes (P.I) ranging between 0.259 to 0.596 (fairly below 1) that obviously indicated an adequate homogeneity between the distributions of these nanocomposites particles.

\subsubsection{Fourier-Transform Infrared Spectroscopy (FT-IR).}

In order to affirm the presence of the drugs in the Curcuminoids-loaded nanocomposite formulations, analyzing the FT-IR results was conducted. Figure 5ii, displayed the spectra of FT-IR patterns for; raw Cur, ThPO, PhPO, PCL-PU- $\beta C D$, and Curcuminoids-loaded nanocomposite samples (M 1, M 3, M 4, M 5, M 7, and M B).

The raw Cur FT-IR spectra profiles revealed a characteristic absorption zone ranging between 3500 and $3300 \mathrm{~cm}^{-1}$, assigning to the presence of the phenolic $-\mathrm{OH}$ vibrational stretching, along with displaying a more particularly sharp stretching band of $-\mathrm{OH}$ at $3430 \mathrm{~cm}^{-}$ ${ }^{1}$ for the raw Cur, reflecting the presence of free hydroxyl groups $(-\mathrm{OH})$ that is referred to the keto-enol residence of the $\alpha$ - $\beta$-unsaturated ketones in the raw Cur. It was in a crystalline form [94]. In Cur- loaded nanocomposite samples (M 3 and M 7), a shifting was noticed from 3430 to $3427 \mathrm{~cm}^{-1}$ in sample M 3 and 3439 from $3430 \mathrm{~cm}^{-1}$ in sample M 7, where both of the peaks at 3427 and $3439 \mathrm{~cm}-1$ appeared to be in wider bands ranging between 3600 and $3250 \mathrm{~cm}^{-1}$, with the absence of the sharp stretching band of $-\mathrm{OH}$, reflecting the existence of intermolecular hydrogen bindings within these nanocomposite samples between the polymeric matrixes and the core materials and thus proving the successful drug encapsulation within such PCL-PU$\beta C D$ nanocomposites matrixes, such interactions could lead to changing the drug structures from a crystalline to an amorphous form.

The raw PCL-PU- $\beta C D$ terminal hydroxyl groups absorption peak at $3432 \mathrm{~cm}^{-1}$ in Figure 5ii, were shifted to lower or higher peaks at 3427, 3439, 3426, 3399, 3434, and 3325 $\mathrm{cm}^{-1}$ with different intensities for; Cur-loaded (M 3 and M 7), ThPO-loaded (M 1 and M 5), and PhPO-loaded (M 4 and M B) nanocomposite samples, respectively, that furtherly indicated the presence of hydrogen linkages in PCL-PU- $\beta C D$ singly and or PCL-PU- $\beta C D$ with Curcuminoidal drugs [95] that could reflect drug encloser within polymeric nanocomposite cavities.

Figure 5ii, also depicted distinct signals for; the PCL-PU- $\beta C D$ copolymer and Curcuminoids-loaded nanocomposite samples, at the range 1107-1102 cm-1 and at the range $1247-1246 \mathrm{~cm}-1$, which were allocated to the characteristic C-O-C vibrational stretching bonds of the reiterated units - $\mathrm{OCH} 2 \mathrm{CH} 2$ of $\beta \mathrm{CD}$ and the vibrational stretching of $-\mathrm{OCO}$ - bonds, respectively. The peaks at the range $2923-2921 \mathrm{~cm}^{-1}$ and at the range $2875-2863 \mathrm{~cm}^{-1}$ were conformed to the characteristic $\mathrm{C}-\mathrm{H}$ absorptional stretching linkages of $-\mathrm{CH} 2 \mathrm{CH} 2$ that were identical to those of epsilon-CL. Also, other weak peaks were observed at the range 1462-1459 
cm-1, which could be according to the $-\mathrm{CH} 2$ vibrational bending and or $-\mathrm{C}-\mathrm{O}$. Plus, clear, strong peaks that were recognized at the range 1725-1732 cm-1 and at the range 1647-1646 cm-1 that were referred expectedly to $\mathrm{C}=\mathrm{O}$ adsorptional bonds.

The fingerprinting peaks of raw ThPO and Cur at 1605 and $1628 \mathrm{~cm}^{-1}$, together with raw $\mathrm{PhPO}$ peak located at $1623 \mathrm{~cm}^{-1}$, were mainly attributed to both of; $\mathrm{C}=\mathrm{C}$ double-bonds and the aromatic double-bonds of $\mathrm{C}=\mathrm{C}$, with another signal at $1598 \mathrm{~cm}^{-1}$ indicating the characteristic benzene rings stretching for both Cur and PhPO drugs, plus a peak at $3067 \mathrm{~cm}^{-1}$ referring to the $\mathrm{C}-\mathrm{H}$ stretching of the ThPO ring, which was all unrecognized in the Curcuminoids-loaded nanocomposite samples. Except for some analogous peaks to those of raw ThPO, Cur, and PhPO that were realized only at $1650-1646 \mathrm{~cm}^{-1}$, indicating the disappearance and shifting (higher or lower shifting) of these characteristic peaks of such native drugs and thus proving the expectations for the occurrence of interactions between the drugs benzene and ThPO rings with the PCL-PU- $\beta C D$ copolymer.

The overall results suggested that Curcuminoidal drugs could be dispersed within the Curcuminoids-loaded nanocomposite formulations and well enclosed within the PCL-PU- $\beta C D$ copolymer [95]. Thus, anticipating the successful formation of Curcuminoids-loaded PCL-PU$\beta C D$ nanocomposites.

\subsubsection{Scanning Electron Microscopy (SEM).}

The Curcuminoids-loaded nanocomposites SEM photos were represented in Figure 5iii, elucidating spherically shaped nano-sized particles linked within a network of mesh-like structures (representing and inferring the polymeric matrixes enclosing the Curcuminoidal drugs as nano-sized globularly shaped particles). Where the right positioned SEM images expressed the Curcuminoids-loaded nanocomposites prepared with the first technique, while the left positioned SEM images represented the Curcuminoids-loaded nanocomposites prepared with the second technique.

\subsubsection{Thermogravimetric analysis (TGA) of the nanocomposites.}

It was quite clear from TGA data represented in Figure 5iv, that M 1, M 3, M 5, and M 7 nanocomposites had lower T5\% and T50\% than PCL-PU-BCD copolymer. This decrease in thermal stability of nanocomposites relative to PCL-PU- $\beta C D$ copolymer has resulted from the disappearance of physical crosslinking between polyurethane chains due to hydrogen binding for nanocomposites [96]. From DTG curves, the first degradation step for M 1 nanocomposite was between $137-300{ }^{\circ} \mathrm{C}$ with maximum degradation temperature (Tmax) $187^{\circ} \mathrm{C}$ followed by second degradation step from $300-502{ }^{\circ} \mathrm{C}$ with $\mathrm{Tmax} 439{ }^{\circ} \mathrm{C}$. While M 3 nanocomposite showed degradation steps between $150-256{ }^{\circ} \mathrm{C}$ with $\mathrm{Tmax} 216{ }^{\circ} \mathrm{C}$ and $256-402$ with Tmax $337^{\circ} \mathrm{C}$. The other nanocomposites manifested three degradation steps from $200-265^{\circ} \mathrm{C}$, Tmax $262{ }^{\circ} \mathrm{C}$; 265-294 ${ }^{\circ} \mathrm{C}, \quad \operatorname{Tmax} 284^{\circ} \mathrm{C}$ and $294-314{ }^{\circ} \mathrm{C}$, Tmax $306{ }^{\circ} \mathrm{C}$ for $\mathrm{M} 5$ nanocomposite whereas M 7 nanocomposite were observed from $159-236^{\circ} \mathrm{C}$, Tmax $214{ }^{\circ} \mathrm{C} ; 264-305^{\circ} \mathrm{C}$, Tmax $287^{\circ} \mathrm{C}$, and $305-341{ }^{\circ} \mathrm{C}$, Tmax $316^{\circ} \mathrm{C}$. It was obvious from degradation profiles that the nanocomposites (M 1, M 3) prepared by the second technique were more thermally stable than that (M 5, M 7) prepared by the first technique. 
a)

i

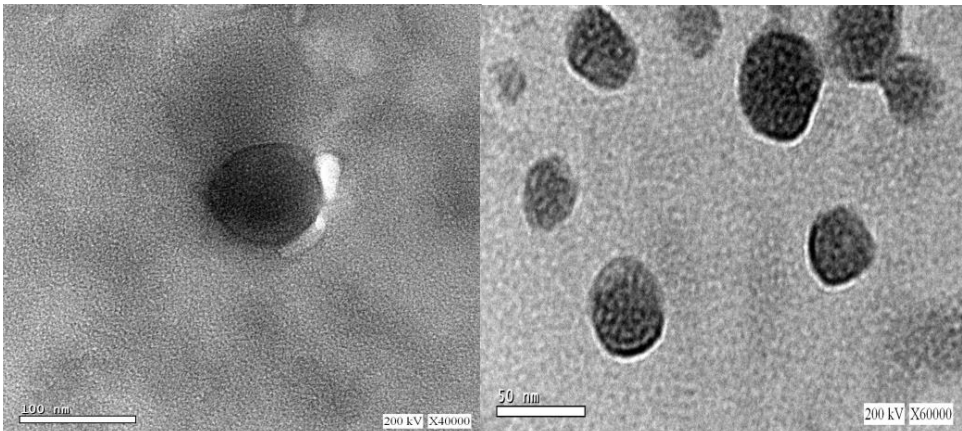

b)

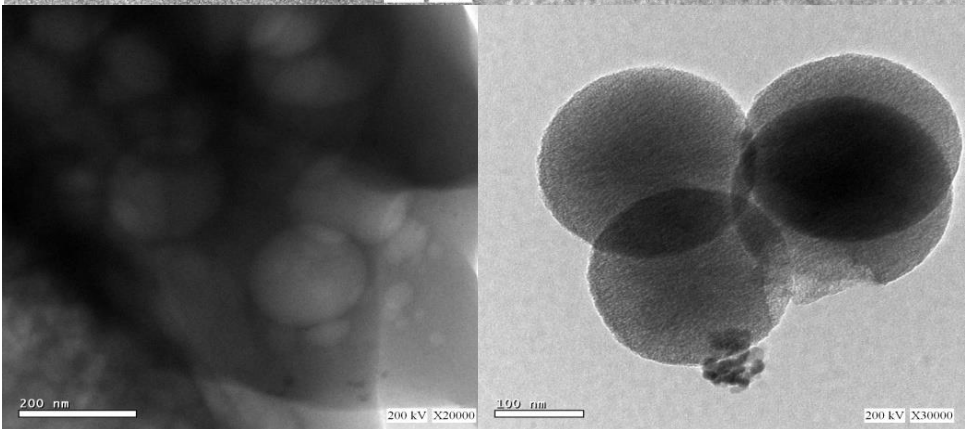

c)
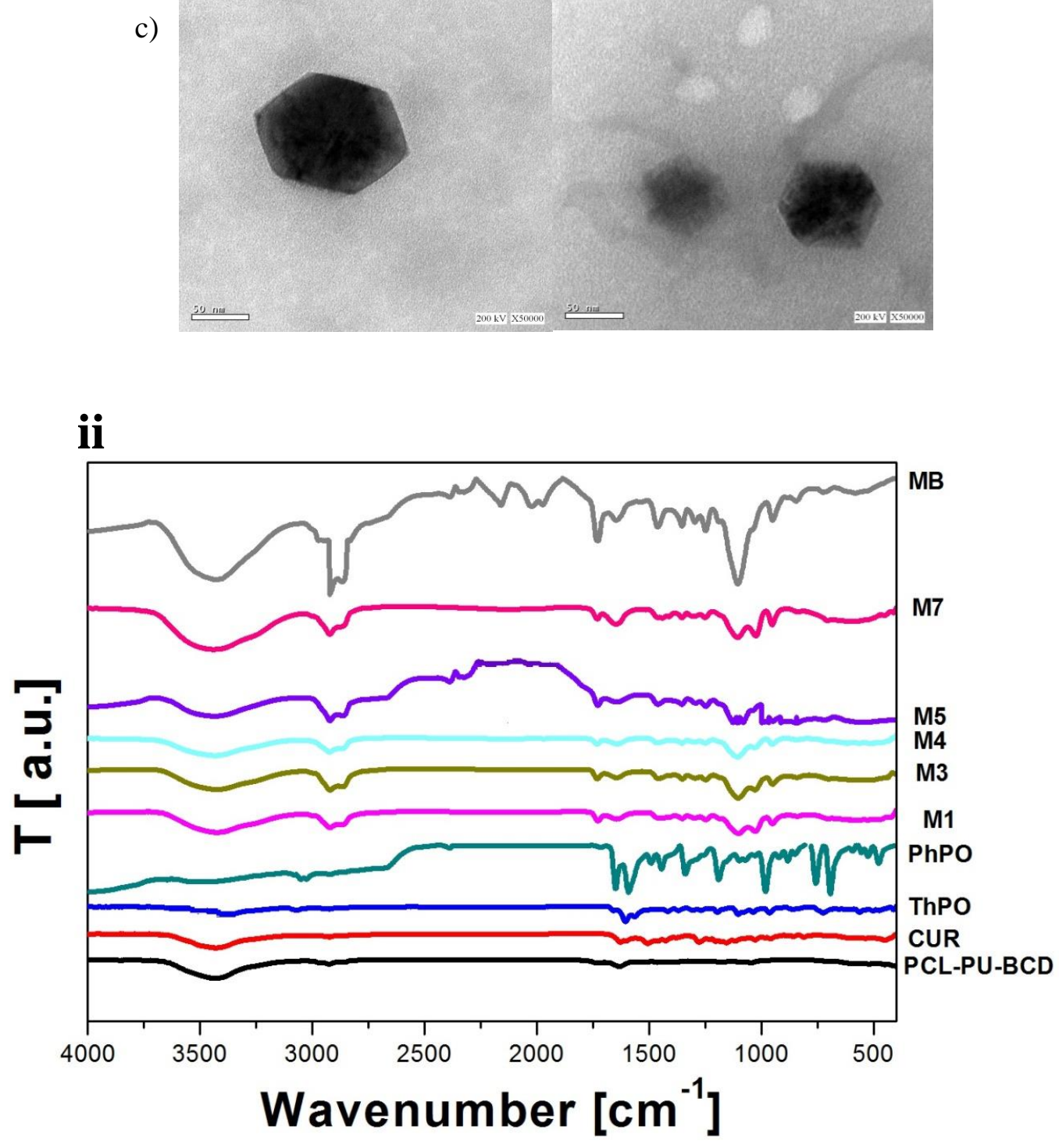


\section{iii}

a)

b)
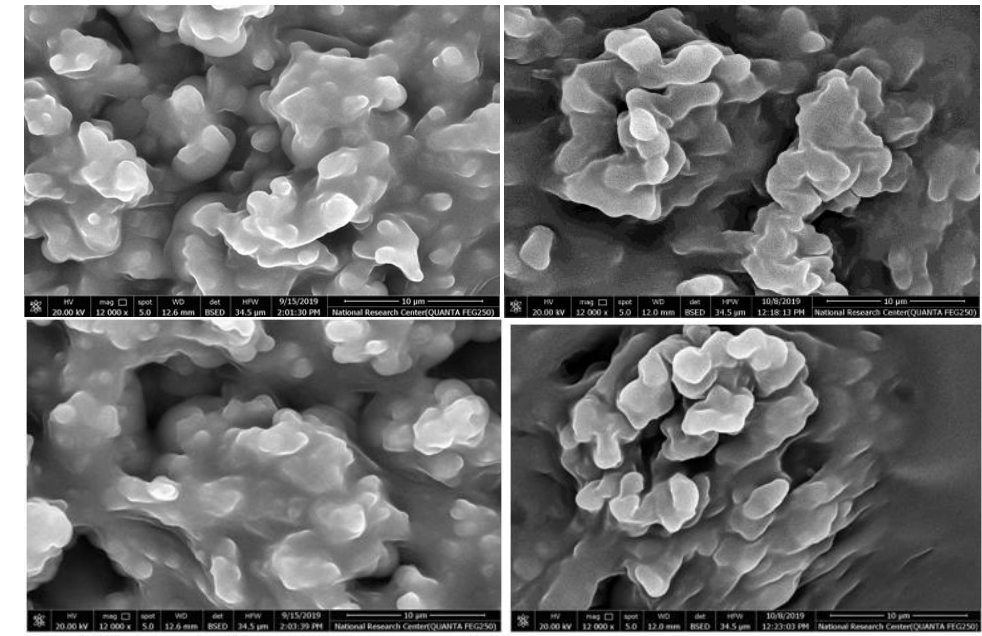

c)

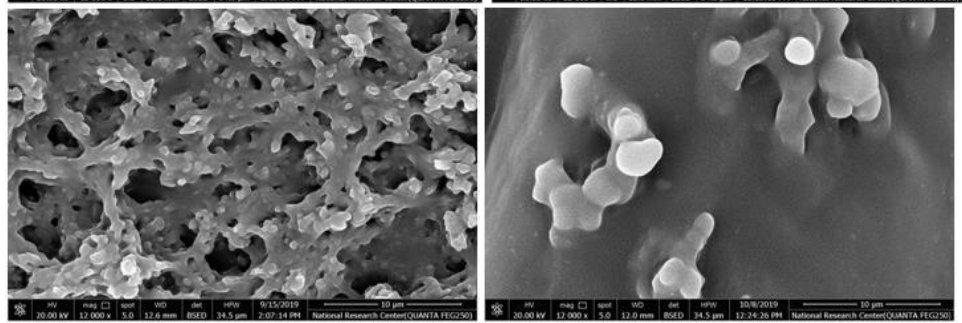

iv
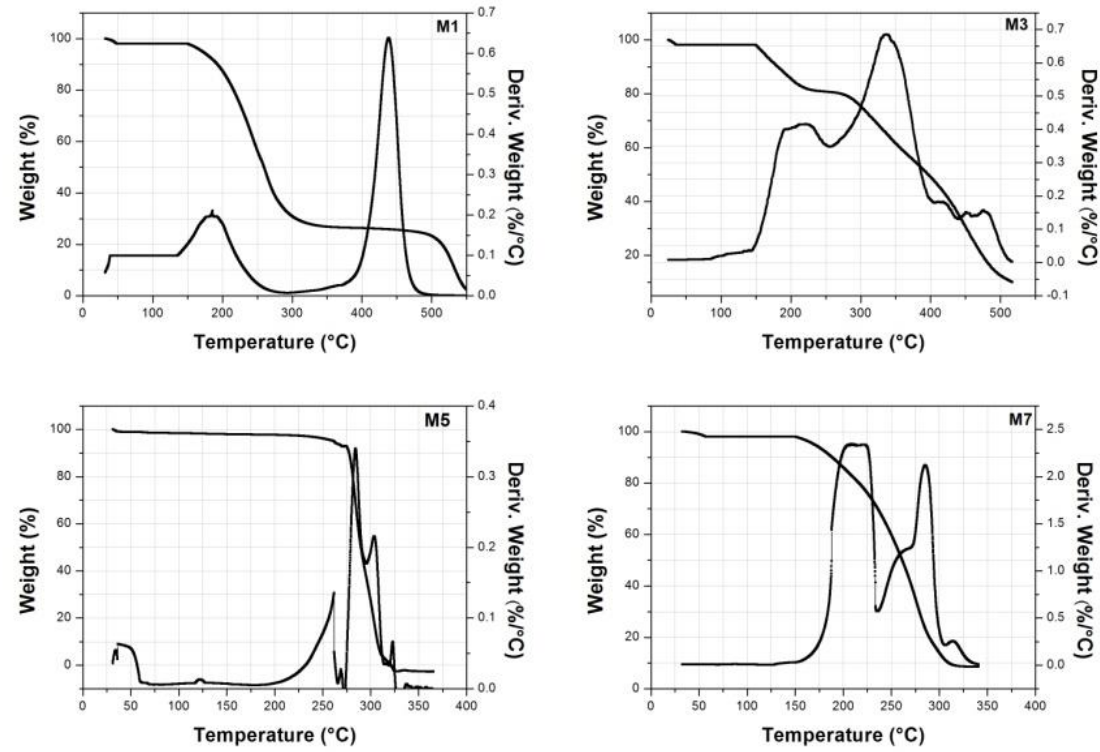

Figure 5. (i) Transmission Electron Microscopy (TEM) of; (a) Cur nanocomposites; (b) ThPO nanocomposites; (c) PhPO nanocomposites; (ii) FT-IR spectrum patterns of raw Cur, ThPO, PhPO, PCL-PU- $\beta C D$, and Curcuminoids-loaded nanocomposite formulae (M 1, M 3, M 4, M 5, M 7, M B); (iii) Scanning Electron Microscope (SEM) of; (a) Cur nanocomposites; (b) ThPO nanocomposites; (c) PhPO nanocomposites; (iv) TGA and DTG curves of Curcuminoids-loaded nanocomposites (M 1, M 3, M 5, M 7).

3.9. In-vitro cell viability and cytotoxicity on normal cells and MTT-based cytotoxicity assay of Curcuminoids-loaded nanocomposites.

Fabrication of drugs into nanocomposite-drug delivery systems revealed a promoted anti-tumor activity and minimized side effects due to their individual high accumulation 
property in tumor tissues [97-99]. Moreover, the encapsulation of hydrophobic anti-cancer drugs in the polymeric nanocomposites enhanced their solubility and furtherly improved their bioavailability [74,100-102]. Many studies demonstrated that curcumin (Cur) has a significant anti-proliferative effect on breast carcinoma cells [103-105]. This study investigated the cytotoxicity effect of Curcuminoids-loaded nanocomposites against normal Vero and MCF-7 cells. A standard MTT assay evaluated the cell viability after exposure to Curcuminoids-loaded nanocomposites at various concentrations for 24 hours, and the IC50\% values were also determined. As shown in Figure 6i, it was clear that the effect of Curcuminoids-loaded nanocomposites on Vero cells was similar and manifested no cytotoxic effect, which indicated the safety of these nanocomposites for biomedical application. This agrees with other documented outcomes obtaining that the PCL-block micellar copolymer carriers were advantageously safe on Vero normal cells due to the combination of PCL copolymer biodegradation and the low molecular weight of $\beta-\mathrm{CD}$, causing expectedly low cytotoxicity [106-108]. Meanwhile, the cell inhibition effect of Curcuminoids-loaded nanocomposites on MCF-7 cells shown in Figure 6ii, was revealingly high. It was found that, the inhibition rates of the MCF-7 cells treated with such nanocomposites including drug concentrations of; $14 \times 10$ $2,7 \times 10-2,37.5 \times 10-3,18.8 \times 10-3 \mu \mathrm{g} / \mathrm{mL}$, were about $90 \%, 79 \%, 57 \%$ and $7 \%$ for M 1 (ThPOnanocomposite, technique 2); $88 \%, 59 \%, 10 \%$ and $0.5 \%$ for M 5 (ThPO- nanocomposite, technique 1); $93 \%, 89 \%, 67 \%$ and $12 \%$ for M 3 (Cur- nanocomposite, technique 2), $91 \%, 70 \%$, $20 \%$ and $5 \%$ for M 7 (Cur- nanocomposite, technique 1); 93\%, 91\%, 87\% and 69\% for M B (PhPO- nanocomposite, technique 2) and 90\%, 72\%, 62\% and 50\% for $\mathrm{M} 4$ (PhPOnanocomposite, technique 1 ). From these results, it was clearly demonstrated that the inhibition effect of drug-loaded polymeric nanocomposites on the MCF-7cells, increased obviously with increasing drug concentrations in such nanocomposites. Moreover, the maximum concentration of drug used was only $0.14 \mu \mathrm{g} / \mathrm{mL}$ that was very low, despite that, it achieved a superior cytotoxic inhibition of MCF-7cells reaching roughly $90 \%$. This indicated that all nanocomposites had potent inhibitory effects on the viabilities of MCF-7 cells. The high potency of drug-loaded nanocomposites could be attributed to boosting the cytotoxic impact of the drug in these nanoparticles [109,110]. Moreover, Curcuminoids-loaded nanocomposites prepared by technique 2 (M 1, M 3, M B) showed slightly higher cytotoxicity relatively to samples prepared by technique 1 (M 4, M 5, M 7) that might be related to their encapsulation efficiency percentages (EE\%), even though they weren't significantly different ( $\mathrm{p}$ higher than 0.05 ). Such high cytotoxicity power of samples prepared by technique 2 (M 1, M 3, M B) matched the documents stating that nanoparticles containing oleic acid could potentiate drug cytotoxicity 106 times more on cancer cell-lines due to their high cellular uptake that is referred to the oleic acid powerful penetration ability [111]. As well, the high cytotoxicity of samples prepared by technique 1 (M 4, M 5, M 7) coincides with statements mentioning that, as PCL co-polymeric nanoparticles had high cytotoxicity among breast cancer cells, it was found that PCL-Pluronic co-polymeric nanoparticles reached significantly higher levels of cytotoxicity, that could be attributed to the Pluronic higher cellular uptake due to its capability to incorporate into the cell membranes [112]. Additionally, the M B sample that achieved the strongest cytotoxicity on MCF-7cells might be correlated to its release attitude $[113,114]$. Although M B nanocomposite attained a sustained release manner of the PhPO drug, its release showed the highest burst effect during the release first hours compared to that of the other nanocomposites, consequently increasing the amount of drug released, realizing the highest cell defeating. 

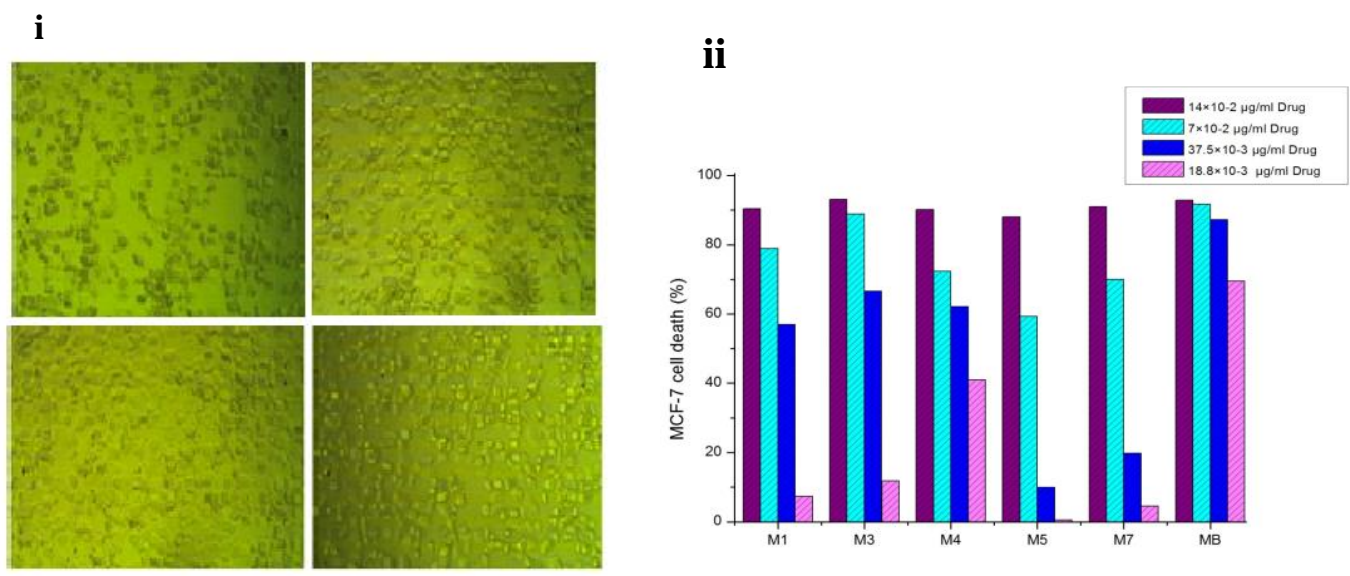

iii

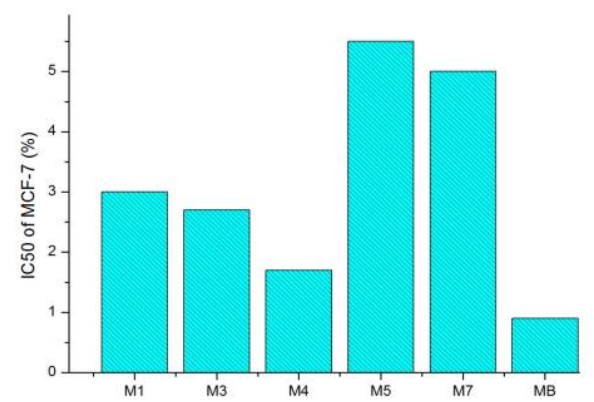

Figure 6. (i) Pictures of Vero cells viability after treatment with synthetic curcuminoids-loaded nanocomposites a) M 1, b) M 4, c) M 5, d) M 7 at $7 \times 10^{-2} \mu \mathrm{g} / \mathrm{mL}$ of the drug; (ii) The MCF-7 cell death $\%$ of the Curcuminoids-loaded nanocomposite formulae; (iii) The IC50\% of the Curcuminoids-loaded nanocomposite formulae.

The half inhibition concentrations (IC50) percentages of MCF-7 cells were; $3 \%, 2.7 \%$, $1.7 \%, 5.5 \%, 5 \%$ and $0.9 \%$ for M 1, M 3, M 4, M 5, M 7 and M B nanocomposites, respectively (Figure 6iii). While the IC50 percentage of pure curcumin after 24 hours incubation with MCF7 cells was 31\% [115]. Tabatabaei Mirakabad, Akbarzadeh, Milani, Zarghami, TaheriAnganeh, Zeighamian, Badrzadeh and Rahmati-Yamchi [115] found that the IC50 percentage of curcumin encapsulated into Poly (lactic-co-glycolic acid)-polyethylene glycol (PLGA-PEG) nanoparticles was $\sim 18 \%$ and demonstrated that the reduction of IC50 percentage of encapsulated curcumin was attributed to the increase of curcumin release from PLGA-PEG nanoparticles surrounding the cancer cells. Reflecting that this study innovated Curcuminoidsloaded polymeric nanocomposites possessed lower IC50 percentage values, besides their promising stronger cytotoxicity [116]. Conforming that, all the prepared nanocomposites strengthened the anti-tumor action of these Curcuminoidal drugs. Making this present study, Curcuminoids-loaded nanocomposites, a new application against MCF-7 breast cancer cell line. Together with the characteristically sustained controlled releasing of PCL-block copolymers based on vesico-micelles, causing these nanocomposites meet the required biocompatibility and biodegradability for applications in therapy [89]. Inferring that the antitumor action of these PCL-block copolymers based vesico-micelles Curcuminoids-loaded nanocomposites could have a recommended potential in cancer therapy applications, especially breast cancer. 


\section{Conclusions}

Through this research work, all the estimated data, including the 1HNMR, FT-IR, and thermal stability analysis, proved the successful synthesis of the PCL-PU- $\beta C D$ copolymer and the Curcuminoidal drug (ThPO). Importantly, this study revealed that the prepared PCL-PU$\beta C D$ co-polymeric vesico-micellar nano-carriers were easily prepared and could successfully and efficiently encapsulate the Curcuminoidal drugs, showing sustained controlled release characteristics with a conspicuous releasing plateau continuing for 336 hours through a slow diffusional mechanism that was superior in systems prepared with the second preparation technique relatively to those prepared with the first preparation technique, but despite that, both techniques result from variances were not significantly different ( $p$ higher than 0.05). The Curcuminoids-loaded nanocomposites possessed smart fashionable polygonal and spheroidal shaped micelles together with roundly shaped vesicles with a favorable nano-sized particle and a plausible homogeneity, confirming together with the SEM and FT-IR data the succeeded formation of the Curcuminoids-loaded PCL-PU- $\beta C D$ nanocomposites. With low cytotoxicity and interesting high IC50 percentages preferably achieved by M B sample, that value wasn't significantly different from the other Curcuminoids-loaded nanocomposites. Thus all formulations of this survey could be recommended as promising carriers in cancer therapies.

\section{Funding}

Such study was financially granted by the National Research Centre Project No. AR110111, Cairo, Egypt.

\section{Acknowledgments}

The paper has no acknowledgments.

\section{Conflict of interest}

The authors declare that they have no conflict of interest.

\section{References}

1. Aminabhavi, T.; Balundgi, R.; Cassidy, P. A review on biodegradable plastics. Polymer-Plastics Technology and Engineering 1990, 29, 235-262, https://doi.org/10.1080/03602559008049843.

2. Biswas, A.; Aswal, V.K.; Sastry, P.; Rana, D.; Maiti, P. Reversible bidirectional shape memory effect in polyurethanes through molecular flipping. Macromolecules 2016, 49, 4889-4897, https://doi.org/10.1021/acs.macromol.6b00536.

3. Mahanta, A.K.; Mittal, V.; Singh, N.; Dash, D.; Malik, S.; Kumar, M.; Maiti, P. Polyurethane-grafted chitosan as new biomaterials for controlled drug delivery. Macromolecules 2015, 48, 2654-2666, https://doi.org/10.1021/acs.macromol.5b00030.

4. Merlin, D.L.; Sivasankar, B. Synthesis and characterization of semi-interpenetrating polymer networks using biocompatible polyurethane and acrylamide monomer. European Polymer Journal 2009, 45, 165-170, https://doi.org/10.1016/j.eurpolymj.2008.10.012.

5. Hong, J.K.; Cooke, S.L.; Whittington, A.R.; Roman, M. Bioactive cellulose nanocrystal-poly ( $\varepsilon-$ caprolactone) nanocomposites for bone tissue engineering applications. Frontiers in bioengineering and biotechnology 2021, 9, 7, https://doi.org/10.3389/fbioe.2021.605924.

6. Woodruff, M.A.; Hutmacher, D.W. The return of a forgotten polymer-Polycaprolactone in the 21st century. Progress in polymer science 2010, 35, 1217-1256, https://doi.org/10.1016/j.progpolymsci.2010.04.002.

7. Merkli, A.; Tabatabay, C.; Gurny, R.; Heller, J. Biodegradable polymers for the controlled release of ocular drugs. Progress in polymer science 1998, 23, 563-580, https://doi.org/10.1016/S0079-6700(97)00048-8. 
8. Du, X.; Song, N.; Yang, Y.-W.; Wu, G.; Ma, J.; Gao, H. Reverse micelles based on $\beta$-cyclodextrinincorporated amphiphilic polyurethane copolymers for protein delivery. Polymer Chemistry 2014, 5, 53005309, https://doi.org/10.1039/C4PY00278D.

9. Zhang, J.; Ma, P.X. Cyclodextrin-based supramolecular systems for drug delivery: recent progress and future perspective. Advanced drug delivery reviews 2013, 65, 1215-1233, https://doi.org/10.1016/j.addr.2013.05.001.

10. Hirayama, F.; Uekama, K. Cyclodextrin-based controlled drug release system. Advanced drug delivery reviews 1999, 36, 125-141, https://doi.org/10.1016/S0169-409X(98)00058-1.

11. Uekama, K.; Hirayama, F.; Irie, T. Cyclodextrin drug carrier systems. Chemical reviews 1998, 98, $2045-$ 2076, https://doi.org/10.1021/cr970025p.

12. Lee, D.S.; Hur, P.; Kim, B.K. Chemical hybridization of waterborne polyurethane with $\beta$-cyclodextrin by sol-gel reaction. Progress in Organic Coatings 2017, 111, 107-111, https://doi.org/10.1016/j.porgcoat.2017.04.039.

13. Harada, A.; Kamachi, M. Complex formation between poly (ethylene glycol) and $\alpha$-cyclodextrin. Macromolecules 1990, 23, 2821-2823, https://doi.org/10.1021/ma00212a039.

14. Loftsson, T.; Brewster, M.E. Pharmaceutical applications of cyclodextrins. 1. Drug solubilization and stabilization. J Pharm Sci 1996, 85, 1017-1025, https://doi.org/10.1021/js950534b.

15. Santos, A.C.; Costa, D.; Ferreira, L.; Guerra, C.; Pereira-Silva, M.; Pereira, I.; Peixoto, D.; Ferreira, N.R.; Veiga, F. Cyclodextrin-based delivery systems for in vivo-tested anticancer therapies. Drug Delivery and Translational Research 2021, 11, 49-71, https://doi.org/10.1007/s13346-020-00778-5.

16. Nair, L.S.; Laurencin, C.T. Biodegradable polymers as biomaterials. Progress in polymer science 2007, 32, 762-798, https://doi.org/10.1016/j.progpolymsci.2007.05.017.

17. Ulery, B.D.; Nair, L.S.; Laurencin, C.T. Biomedical applications of biodegradable polymers. J Polym Sci B Polym Phys 2011, 49, 832-864, https://doi.org/10.1002/polb.22259.

18. Mondal, D.; Venkatraman, S.S. Formulation and characterization of naked DNA and complexed DNA loaded polymer films. Materials Science and Engineering: $C$ 2011, 31, 224-229, https://doi.org/10.1016/j.msec.2010.08.021.

19. Natu, M.V.; Gaspar, M.N.; Ribeiro, C.A.F.; Correia, I.J.; Silva, D.; de Sousa, H.C.; Gil, M. A poly ( $\varepsilon-$ caprolactone) device for sustained release of an anti-glaucoma drug. Biomedical Materials 2011, 6, 025003, https://doi.org/10.1088/1748-6041/6/2/025003.

20. Minassi, A.; Sánchez-Duffhues, G.; Collado, J.A.; Muñoz, E.; Appendino, G. Dissecting the pharmacophore of curcumin. Which structural element is critical for which action? Journal of natural products 2013, 76, 1105-1112, https://doi.org/10.1021/np400148e.

21. Anand, P.; Thomas, S.G.; Kunnumakkara, A.B.; Sundaram, C.; Harikumar, K.B.; Sung, B.; Tharakan, S.T.; Misra, K.; Priyadarsini, I.K.; Rajasekharan, K.N. Biological activities of curcumin and its analogues (Congeners) made by man and Mother Nature. Biochemical pharmacology 2008, 76, 1590-1611, https://doi.org/10.1016/j.bcp.2008.08.008.

22. Youssef, K.M.; El-Sherbeny, M.A.; El-Shafie, F.S.; Farag, H.A.; Al-Deeb, O.A.; Awadalla, S.A.A. Synthesis of curcumin analogues as potential antioxidant, cancer chemopreventive agents. Archiv der Pharmazie: An International Journal Pharmaceutical and Medicinal Chemistry 2004, 337, 42-54, https://doi.org/10.1002/ardp.200300763.

23. Sardjiman, S.; Reksohadiprodjo, M.; Hakim, L.; Van der Goot, H.; Timmerman, H. 1, 5-Diphenyl-1, 4pentadiene-3-ones and cyclic analogues as antioxidative agents. Synthesis and structure-activity relationship. European Journal of Medicinal Chemistry 1997, 32, 625-630, https://doi.org/10.1016/S02235234(97)83288-6.

24. Liang, G.; Li, X.; Chen, L.; Yang, S.; Wu, X.; Studer, E.; Gurley, E.; Hylemon, P.B.; Ye, F.; Li, Y. Synthesis and anti-inflammatory activities of mono-carbonyl analogues of curcumin. Bioorganic \& medicinal chemistry letters 2008, 18, 1525-1529, https://doi.org/10.1016/j.bmcl.2007.12.068.

25. Liang, G.; Shao, L.; Wang, Y.; Zhao, C.; Chu, Y.; Xiao, J.; Zhao, Y.; Li, X.; Yang, S. Exploration and synthesis of curcumin analogues with improved structural stability both in vitro and in vivo as cytotoxic agents. Bioorganic \& medicinal chemistry 2009, 17, 2623-2631, https://doi.org/10.1016/j.bmc.2008.10.044.

26. Kohyama, A.; Yamakoshi, H.; Hongo, S.; Kanoh, N.; Shibata, H.; Iwabuchi, Y. Structure-activity relationships of the anti-tumor C5-curcuminoid GO-Y030. Molecules 2015, 20, 15374-15391, https://doi.org/10.3390/molecules200815374.

27. Yin, S.; Zheng, X.; Yao, X.; Wang, Y.; Liao, D. Synthesis and anti-cancer activity of mono-carbonyl analogues of curcumin. J Cancer Ther 2013, 4, 113-123.

28. Yamakoshi, H.; Ohori, H.; Kudo, C.; Sato, A.; Kanoh, N.; Ishioka, C.; Shibata, H.; Iwabuchi, Y. Structureactivity relationship of $\mathrm{C} 5$-curcuminoids and synthesis of their molecular probes thereof. Bioorganic \& medicinal chemistry 2010, 18, 1083-1092, https://doi.org/10.1016/j.bmc.2009.12.045.

29. Al-Howail, H.A.; Hakami, H.A.; Al-Otaibi, B.; Al-Mazrou, A.; Daghestani, M.H.; Al-Jammaz, I.; Al-Khalaf, H.H.; Aboussekhra, A. PAC down-regulates estrogen receptor alpha and suppresses epithelial-tomesenchymal transition in breast cancer cells. BMC cancer 2016, 16, 540. 
30. Al-Hujaily, E.M.; Mohamed, A.G.; Al-Sharif, I.; Youssef, K.M.; Manogaran, P.S.; Al-Otaibi, B.; Al-Haza'a, A.; Al-Jammaz, I.; Al-Hussein, K.; Aboussekhra, A. PAC, a novel curcumin analogue, has anti-breast cancer properties with higher efficiency on ER-negative cells. Breast cancer research and treatment 2011, 128, 97 107, https://doi.org/10.1007/s10549-010-1089-3.

31. Somers-Edgar, T.J.; Taurin, S.; Larsen, L.; Chandramouli, A.; Nelson, M.A.; Rosengren, R.J. Mechanisms for the activity of heterocyclic cyclohexanone curcumin derivatives in estrogen receptor negative human breast cancer cell lines. Investigational new drugs 2011, 29, 87-97, https://doi.org/10.1007/s10637-009-93390 .

32. Abou Taleb, S.; Darwish, A.B.; Abood, A.; Mohamed, A.M. Investigation of a new horizon antifungal activity with enhancing the antimicrobial efficacy of ciprofloxacin and its binary mixture via their encapsulation in nanoassemblies: in vitro and in vivo evaluation. Drug Development Research 2020, 81, 374388, https://doi.org/10.1002/ddr.21632.

33. Karthikeyan, A.; Senthil, N.; Min, T. Nanocurcumin: A promising candidate for therapeutic applications. Frontiers in Pharmacology 2020, 11, https://doi.org/10.3389/fphar.2020.00487.

34. Sreeharsha, N.; Chitrapriya, N.; Jang, Y.J.; Kenchappa, V. Evaluation of nanoparticle drug-delivery systems used in preclinical studies. Therapeutic Delivery 2021, 12, 325-336, https://doi.org/10.4155/tde-2020-0116.

35. Allegra, A.; Penna, G.; Alonci, A.; Rizzo, V.; Russo, S.; Musolino, C. Nanoparticles in oncology: the new theragnostic molecules. Anti-Cancer Agents in Medicinal Chemistry (Formerly Current Medicinal Chemistry-Anti-Cancer Agents) 2011, 11, 669-686, https://doi.org/10.2174/187152011796817682.

36. Shinde, P.; Parve, B.; Rawat, S.; Rathod, S.; Varandal, A. Different approaches towards the solubility enhancement of drug: A review. Journal of Advanced Pharmacy Education \& Research 2014, 3, 10.

37. Tsai, Y.-M.; Chien, C.-F.; Lin, L.-C.; Tsai, T.-H. Curcumin and its nano-formulation: the kinetics of tissue distribution and blood-brain barrier penetration. International journal of pharmaceutics 2011, 416, 331-338, https://doi.org/10.1016/j.ijpharm.2011.06.030.

38. Allegra, A.; Innao, V.; Russo, S.; Gerace, D.; Alonci, A.; Musolino, C. Anticancer activity of curcumin and its analogues: preclinical and clinical studies. Cancer investigation 2017, 35, 1-22, https://doi.org/10.1080/07357907.2016.1247166.

39. Hanna, D.H.; Saad, G.R. Nanocurcumin: preparation, characterization and cytotoxic effects towards human laryngeal cancer cells. RSC Advances 2020, 10, 20724-20737, https://doi.org/10.1039/D0RA03719B.

40. Demicheli, C.; Ochoa, R.; da Silva, J.B.; Falcão, C.A.; Rossi-Bergmann, B.; de Melo, A.L.; Sinisterra, R.D.; Frézard, F. Oral delivery of meglumine antimoniate- $\beta$-cyclodextrin complex for treatment of leishmaniasis. Antimicrobial agents and chemotherapy 2004, 48, 100-103, https://doi.org/10.1128/AAC.48.1.100103.2004.

41. Lakkakula, J.R.; Maçedo Krause, R.W. A vision for cyclodextrin nanoparticles in drug delivery systems and pharmaceutical applications. Nanomedicine 2014, 9, 877-894, https://doi.org/10.2217/nnm.14.41.

42. Kumar, V.; Kumar, R.; Jain, V.; Nagpal, S. Preparation and characterization of nanocurcumin based hybrid virosomes as a drug delivery vehicle with enhanced anticancerous activity and reduced toxicity. Scientific reports 2021, 11, 1-14, https://doi.org/10.1038/s41598-020-79631-1.

43. Kasinathan, N.; Amirthalingam, M.; Reddy, N.D.; Jagani, H.V.; Volety, S.M.; Rao, J.V. In-situ implant containing PCL-curcumin nanoparticles developed using design of experiments. Drug delivery 2016, 23, 1007-1015, https://doi.org/10.3109/10717544.2014.927021si.

44. M Luisa, D.P.-A.; Griselda, R.-M.; Valentín, M.-L.; Carmina, O.-S.; Cristina, V.-M.; JJ, M.; Maykel, G.-T.; David, Q.-G.; Roberto, S.-S.; Gerardo, L.-G. Curcumin-loaded poly-e-caprolactone nanoparticles show antioxidant and cytoprotective effects in the presence of reactive oxygen species. Journal of Bioactive and Compatible Polymers 2020, 35, 270-285, https://doi.org/10.1177/0883911520921499.

45. Edis, Z.; Wang, J.; Waqas, M.K.; Ijaz, M.; Ijaz, M. Nanocarriers-mediated drug delivery systems for anticancer agents: an overview and perspectives. International Journal of Nanomedicine 2021, 16, 1313, https://doi.org/10.2147/IJN.S289443.

46. Sinha, V.; Bansal, K.; Kaushik, R.; Kumria, R.; Trehan, A. Poly-€-caprolactone microspheres and nanospheres: an overview. International journal of pharmaceutics 2004, 278, 1-23, https://doi.org/10.1016/j.ijpharm.2004.01.044.

47. Varan, C.; Bilensoy, E. Cationic PEGylated polycaprolactone nanoparticles carrying post-operation docetaxel for glioma treatment. Beilstein journal of nanotechnology 2017, 8, 1446-1456, https://doi.org/10.3762/bjnano.8.144.

48. Hossain, M.S.; Mohamed, F.; Shafri, M.A.M. Poly (trimethylene carbonate-co-caprolactone): An emerging drug delivery nanosystem in pharmaceutics. Biomaterials and Biomechanics in Bioengineering 2020, 5, 6586, https://doi.org/10.12989/bme.2020.5.1.065.

49. Choi, C.; Chae, S.Y.; Nah, J.-W. Thermosensitive poly (N-isopropylacrylamide)-b-poly ( $\varepsilon$-caprolactone) nanoparticles for efficient drug delivery system. Polymer 2006, 47, 4571-4580, https://doi.org/10.1016/j.polymer.2006.05.011.

50. Prabu, P.; Chaudhari, A.A.; Dharmaraj, N.; Khil, M.; Park, S.; Kim, H. Preparation, characterization, in-vitro drug release and cellular uptake of poly (caprolactone) grafted dextran co-polymeric nanoparticles loaded 
with anti-cancer drug. Journal of Biomedical Materials Research Part A 2009, 90, 1128-1136, https://doi.org/10.1002/jbm.a.32163.

51. Li, G.; Li, D.; Niu, Y.; He, T.; Chen, K.C.; Xu, K. Alternating block polyurethanes based on PCL and PEG as potential nerve regeneration materials. Journal of Biomedical Materials Research Part A 2014, 102, 685697, https://doi.org/10.1002/jbm.a.34732.

52. Jiang, J.; Ao, J.; He, C.; Xiong, J.; Zhao, J.; Liu, J.; You, S.; Jiang, H. Preparation and characterisation of ginkgolide nanoparticles via the emulsion solvent evaporation method. Micro \& Nano Letters 2018, 13, 636640, https://doi.org/10.1049/mnl.2017.0906.

53. Le Thi Mai Hoa, N.T. Chi, Nguyen Minh Triet, Le Ngoc ThanhNhan, Dang Mau Chien. Preparation of drug nanoparticles by emulsion evaporation method. Journal of physics 2009, 187, 1742-6596, https://doi.org/10.1088/1742-6596/187/1/012047.

54. Wang, Y.; Li, P.; Truong-Dinh Tran, T.; Zhang, J.; Kong, L. Manufacturing techniques and surface engineering of polymer based nanoparticles for targeted drug delivery to cancer. Nanomaterials 2016, 6, 26, https://doi.org/10.3390/nano6020026.

55. Bouchemal, K.; Briançon, S.; Perrier, E.; Fessi, H. Nano-emulsion formulation using spontaneous emulsification: solvent, oil and surfactant optimisation. International journal of pharmaceutics 2004, 280, 241-251, https://doi.org/10.1016/j.ijpharm.2004.05.016.

56. Thickett, S.C.; Gilbert, R.G. Emulsion polymerization: State of the art in kinetics and mechanisms. Polymer 2007, 48, 6965-6991, https://doi.org/10.1016/j.polymer.2007.09.031.

57. Asua, J.M. Emulsion polymerization: from fundamental mechanisms to process developments. Journal of Polymer Science Part A: Polymer Chemistry 2004, 42, 1025-1041, https://doi.org/10.1002/pola.11096.

58. Ge, H.; Hu, Y.; Yang, S.; Jiang, X.; Yang, C. Preparation, characterization, and drug release behaviors of drug-loaded $\varepsilon$-caprolactone/L-lactide copolymer nanoparticles. Journal of applied polymer science 2000, 75, 874-882, https://doi.org/10.1002/(SICI)1097-4628(20000214)75:7<874::AID-APP3>3.0.CO;2-G.

59. $\mathrm{Xu}, \mathrm{G}$;; Sunada, H. Influence of formulation change on drug release kinetics from hydroxypropylmethylcellulose matrix tablets. Chemical and pharmaceutical bulletin 1995, 43, 483-487, https://doi.org/10.1248/cpb.43.483.

60. Ritger, P.L.; Peppas, N.A. A simple equation for description of solute release II. Fickian and anomalous release from swellable devices. Journal of controlled release 1987, 5, 37-42, https://doi.org/10.1016/01683659(87)90035-6.

61. Higuchi, T. Mechanism of sustained-action medication. Theoretical analysis of rate of release of solid drugs dispersed in solid matrices. Journal of pharmaceutical sciences 1963, 52, 1145-1149, https://doi.org/10.1002/jps.2600521210.

62. Siepmann, J.; Peppas, N. Modeling of drug release from delivery systems based on hydroxypropyl methylcellulose (HPMC). Advanced drug delivery reviews 2001, 64, 163-174, https://doi.org/10.1016/j.addr.2012.09.028.

63. Korsmeyer, R.W.; Gurny, R.; Doelker, E.; Buri, P.; Peppas, N.A. Mechanisms of solute release from porous hydrophilic polymers. International journal of pharmaceutics 1983, 15, 25-35, https://doi.org/10.1016/03785173(83)90064-9.

64. Patel, M.M.; Patel, B.M. Crossing the blood-brain barrier: recent advances in drug delivery to the brain. $C N S$ drugs 2017, 31, 109-133, https://doi.org/10.1007/s40263-016-0405-9.

65. Sudha, S.; Sundaraganesan, N.; Vanchinathan, K.; Muthu, K.; Meenakshisundaram, S. Spectroscopic (FTIR, FT-Raman, NMR and UV) and molecular structure investigations of 1, 5-diphenylpenta-1, 4-dien-3-one: A combined experimental and theoretical study. Journal of Molecular Structure 2012, 1030, 191-203, https://doi.org/10.1016/j.molstruc.2012.04.030.

66. Askari, F.; Barikani, M.; Barmar, M. Study on thermal stability of polyurethane-urea based on polysiloxane and polycaprolactone diols. Korean Journal of Chemical Engineering 2013, 30, 2093-2099, https://doi.org/10.1007/s11814-013-0139-z.

67. Levchik, S.V.; Weil, E.D. Thermal decomposition, combustion and fire-retardancy of polyurethanes-a review of the recent literature. Polymer International 2004, 53, 1585-1610, https://doi.org/10.1002/pi.1314.

68. Kohata, S.; Jyodoi, K.; Ohyoshi, A. Thermal decomposition of cyclodextrins $(\alpha-, \beta-, \gamma-$, and modified $\beta$-CyD) and of metal- $(\beta-\mathrm{CyD})$ complexes in the solid phase. Thermochimica acta 1993, 217, 187-198, https://doi.org/10.1016/0040-6031(93)85107-K.

69. Panwiriyarat, W.; Tanrattanakul, V.; Pilard, J.-F.; Pasetto, P.; Khaokong, C. Preparation and properties of bio-based polyurethane containing polycaprolactone and natural rubber. Journal of Polymers and the Environment 2013, 21, 807-815, https://doi.org/10.1007/s10924-012-0567-6.

70. Jasim, F.; Talib, T. Some observations on the thermal behaviour of curcumin under air and argon atmospheres. Journal of thermal analysis 1992, 38, 2549-2552, https://doi.org/10.1007/BF01974631.

71. Souguir, H.; Salaün, F.; Douillet, P.; Vroman, I.; Chatterjee, S. Nanoencapsulation of curcumin in polyurethane and polyurea shells by an emulsion diffusion method. Chemical Engineering Journal 2013, 221, 133-145, https://doi.org/10.1016/j.cej.2013.01.069.

72. Yue, X.; Qiao, Y.; Qiao, N.; Guo, S.; Xing, J.; Deng, L.; Xu, J.; Dong, A. Amphiphilic Methoxy Poly (ethylene glycol)-b-poly ( $\varepsilon$-caprolactone)-b-poly (2-dimethylaminoethyl methacrylate) Cationic Copolymer 
Nanoparticles as a Vector for Gene and Drug Delivery. Biomacromolecules 2010, 11, 2306-2312, https://doi.org/10.1021/bm100410m.

73. Zhang, W.; He, J.; Liu, Z.; Ni, P.; Zhu, X. Biocompatible and pH-responsive triblock copolymer mPEG-bPCL-b-PDMAEMA: Synthesis, self-assembly, and application. Journal of Polymer Science Part A: Polymer Chemistry 2010, 48, 1079-1091, https://doi.org/10.1002/pola.23863.

74. Wei, X.; Gong, C.; Gou, M.; Fu, S.; Guo, Q.; Shi, S.; Luo, F.; Guo, G.; Qiu, L.; Qian, Z. Biodegradable poly (E-caprolactone)-poly (ethylene glycol) copolymers as drug delivery system. International journal of pharmaceutics 2009, 381, 1-18, https://doi.org/10.1016/j.ijpharm.2009.07.033.

75. Sharma, N.; Madan, P.; Lin, S. Effect of process and formulation variables on the preparation of parenteral paclitaxel-loaded biodegradable polymeric nanoparticles: A co-surfactant study. asian journal of pharmaceutical sciences 2016, 11, 404-416, https://doi.org/10.1016/j.ajps.2015.09.004.

76. Dhillon, V.; Sharma, S.; Jain, S.; Sharma, A.; Arora, S. Formulation characterization and evaluation of new topical 5-fu by drug entrapment in oleic acid vesicles. American Journal of PharmTech Research 2011, 1, 116.

77. Sahu, A.; Kasoju, N.; Goswami, P.; Bora, U. Encapsulation of curcumin in Pluronic block copolymer micelles for drug delivery applications. Journal of biomaterials applications 2011, 25, 619-639, https://doi.org/10.1177/0885328209357110.

78. Feng, R.; Song, Z.; Zhai, G. Preparation and in vivo pharmacokinetics of curcumin-loaded PCL-PEG-PCL triblock co-polymeric nanoparticles. International journal of nanomedicine 2012, 7, 4089, https://doi.org/10.2147/IJN.S33607.

79. Danafar, H. Study of the composition of polycaprolactone/poly (ethylene glycol)/polycaprolactone copolymer and drug-to-polymer ratio on drug loading efficiency of curcumin to nanoparticles. Jundishapur Journal of Natural Pharmaceutical Products 2017, 12, https://doi.org/10.5812/jjnpp.34179.

80. Ereno, C.; Guimarães, S.A.C.; Pasetto, S.; Herculano, R.D.; Silva, C.P.; Graeff, C.F.; Tavano, O.; Baffa, O.; Kinoshita, A. Latex use as an occlusive membrane for guided bone regeneration. Journal of Biomedical Materials Research Part A 2010, 95, 932-939, https://doi.org/10.1002/jbm.a.32919.

81. Manjili, H.K.; Ghasemi, P.; Malvandi, H.; Mousavi, M.S.; Attari, E.; Danafar, H. Pharmacokinetics and in vivo delivery of curcumin by co-polymeric mPEG-PCL micelles. European Journal of Pharmaceutics and Biopharmaceutics 2017, 116, 17-30, https://doi.org/10.1016/j.ejpb.2016.10.003.

82. Dash, S.; Murthy, P.N.; Nath, L.; Chowdhury, P. Kinetic modeling on drug release from controlled drug delivery systems. Acta Pol Pharm 2010, 67, 217-223.

83. Han, J.; Zhu, D.; Gao, C. Fast bulk click polymerization approach to linear and hyperbranched alternating multiblock copolymers. Polymer Chemistry 2013, 4, 542-549, https://doi.org/10.1039/C2PY20432K.

84. Lu, C.; Guo, S.r.; Zhang, Y.; Yin, M. Synthesis and aggregation behavior of four types of different shaped PCL-PEG block copolymers. Polymer international 2006, 55, 694-700, https://doi.org/10.1002/pi.2034.

85. Bae, S.J.; Suh, J.M.; Sohn, Y.S.; Bae, Y.H.; Kim, S.W.; Jeong, B. Thermogelling poly (caprolactone-bethylene glycol-b-caprolactone) aqueous solutions. Macromolecules 2005, 38, 5260-5265, https://doi.org/10.1021/ma050489m.

86. Pang, Z.; Lu, W.; Gao, H.; Hu, K.; Chen, J.; Zhang, C.; Gao, X.; Jiang, X.; Zhu, C. Preparation and brain delivery property of biodegradable polymersomes conjugated with OX26. Journal of Controlled Release 2008, 128, 120-127, https://doi.org/10.1016/j.jconrel.2008.03.007.

87. Ghoroghchian, P.P.; Li, G.; Levine, D.H.; Davis, K.P.; Bates, F.S.; Hammer, D.A.; Therien, M.J. Bioresorbable vesicles formed through spontaneous self-assembly of amphiphilic poly (ethylene oxide)block-polycaprolactone. Macromolecules 2006, 39, 1673-1675, https://doi.org/10.1021/ma0519009.

88. Chang, C.; Wei, H.; Quan, C.Y.; Li, Y.Y.; Liu, J.; Wang, Z.C.; Cheng, S.X.; Zhang, X.Z.; Zhuo, R.X. Fabrication of thermosensitive PCL-PNIPAAm-PCL triblock co-polymeric micelles for drug delivery. Journal of Polymer Science Part A: Polymer Chemistry 2008, 46, 3048-3057, https://doi.org/10.1002/pola.22645.

89. Wittemann, A.; Azzam, T.; Eisenberg, A. Biocompatible polymer vesicles from biamphiphilic triblock copolymers and their interaction with bovine serum albumin. Langmuir 2007, 23, 2224-2230, https://doi.org/10.1021/la062805b.

90. Kim, S.Y.; Ha, J.C.; Lee, Y.M. Poly (ethylene oxide)-poly (propylene oxide)-poly (ethylene oxide)/poly ( $\epsilon-$ caprolactone)(PCL) amphiphilic block co-polymeric nanospheres: II. Thermo-responsive drug release behaviors. Journal of controlled release 2000, 65, 345-358, https://doi.org/10.1016/S0168-3659(99)002072 .

91. Yadav, A.K.; Mishra, P.; Jain, S.; Mishra, P.; Mishra, A.K.; Agrawal, G. Preparation and characterization of HA-PEG-PCL intelligent core-corona nanoparticles for delivery of doxorubicin. Journal of drug targeting 2008, 16, 464-478, https://doi.org/10.1080/10611860802095494.

92. Gou, M.; Zheng, L.; Peng, X.; Men, K.; Zheng, X.; Zeng, S.; Guo, G.; Luo, F.; Zhao, X.; Chen, L. Poly ( $\varepsilon-$ caprolactone)-poly (ethylene glycol)-poly ( $\varepsilon$-caprolactone)(PCL-PEG-PCL) nanoparticles for honokiol delivery in vitro. International journal of pharmaceutics 2009, 375, 170-176, https://doi.org/10.1016/j.ijpharm.2009.04.007. 
93. Seijo, B.; Fattal, E.; Roblot-Treupel, L.; Couvreur, P. Design of nanoparticles of less than 50 nm diameter: preparation, characterization and drug loading. International Journal of Pharmaceutics 1990, 62, 1-7, https://doi.org/10.1016/0378-5173(90)90024-X.

94. Yallapu, M.M.; Jaggi, M.; Chauhan, S.C. $\beta$-Cyclodextrin-curcumin self-assembly enhances curcumin delivery in prostate cancer cells. Colloids and Surfaces B: Biointerfaces 2010, 79, 113-125, https://doi.org/10.1016/j.colsurfb.2010.03.039.

95. Mohanty, C.; Sahoo, S.K. The in vitro stability and in vivo pharmacokinetics of curcumin prepared as an aqueous nanoparticulate formulation. Biomaterials 2010, 31, 6597-6611, https://doi.org/10.1016/j.biomaterials.2010.04.062.

96. Ashjari, M.; Mahdavian, A.R.; Ebrahimi, N.G.; Mosleh, Y. Efficient dispersion of magnetite nanoparticles in the polyurethane matrix through solution mixing and investigation of the nanocomposite properties. Journal of Inorganic and Organometallic Polymers and Materials 2010, 20, 213-219, https://doi.org/10.1007/s10904-010-9337-X.

97. Oerlemans, C.; Bult, W.; Bos, M.; Storm, G.; Nijsen, J.F.W.; Hennink, W.E. Polymeric micelles in anticancer therapy: targeting, imaging and triggered release. Pharmaceutical research 2010, 27, 2569-2589, https://doi.org/10.1007/s11095-010-0233-4.

98. Yao, Y.; Zhou, Y.; Liu, L.; Xu, Y.; Chen, Q.; Wang, Y.; Wu, S.; Deng, Y.; Zhang, J.; Shao, A. Nanoparticlebased drug delivery in cancer therapy and its role in overcoming drug resistance. Frontiers in Molecular Biosciences 2020, 7, https://doi.org/10.3389/fmolb.2020.00193.

99. Güven, E. Nanoparticles for Anticancer Drug Delivery. In Nanotechnology Applications in Health and Environmental Sciences, Saglam, N., Korkusuz, F., Prasad, R., Eds. Springer International Publishing: Cham, 2021; https://doi.org/10.1007/978-3-030-64410-9_4.

100.Park, E.K.; Lee, S.B.; Lee, Y.M. Preparation and characterization of methoxy poly (ethylene glycol)/poly ( $\varepsilon-$ caprolactone) amphiphilic block co-polymeric nanospheres for tumor-specific folate-mediated targeting of anti-cancer drugs. Biomaterials 2005, 26, 1053-1061, https://doi.org/10.1016/j.biomaterials.2004.04.008.

101.Dang, Y.; Guan, J. Nanoparticle-based drug delivery systems for cancer therapy. Smart Materials in Medicine 2020, https://doi.org/10.1016/j.smaim.2020.04.001.

102.Ulldemolins, A.; Seras-Franzoso, J.; Andrade, F.; Rafael, D.; Abasolo, I.; Gener, P.; Schwartz Jr, S. Perspectives of nano-carrier drug delivery systems to overcome cancer drug resistance in the clinics. Cancer Drug Resistance 2021, 4, 44-68, https://doi.org/10.20517/cdr.2020.59.

103.Hallman, K.; Aleck, K.; Dwyer, B.; Lloyd, V.; Quigley, M.; Sitto, N.; Siebert, A.E.; Dinda, S. The effects of turmeric (curcumin) on tumor suppressor protein (p53) and estrogen receptor (ER $\alpha)$ in breast cancer cells. Breast Cancer: Targets and Therapy 2017, 9, 153, https://doi.org/10.2147/BCTT.S125783.

104.Liu, Q.; Loo, W.T.; Sze, S.; Tong, Y. Curcumin inhibits cell proliferation of MDA-MB-231 and BT-483 breast cancer cells mediated by down-regulation of NFאB, cyclinD and MMP-1 transcription. Phytomedicine 2009, 16, 916-922, https://doi.org/10.1016/j.phymed.2009.04.008.

105.Shao, Z.M.; Shen, Z.Z.; Liu, C.H.; Sartippour, M.R.; Go, V.L.; Heber, D.; Nguyen, M. Curcumin exerts multiple suppressive effects on human breast carcinoma cells. International journal of cancer 2002, 98, 234240, https://doi.org/10.1002/ijc.10183.

106.Zhu, C.; Jung, S.; Luo, S.; Meng, F.; Zhu, X.; Park, T.G.; Zhong, Z. Co-delivery of siRNA and paclitaxel into cancer cells by biodegradable cationic micelles based on PDMAEMA-PCL-PDMAEMA triblock copolymers. Biomaterials 2010, 31, 2408-2416, https://doi.org/10.1016/j.biomaterials.2009.11.077.

107.Loh, X.J.; Yee, B.J.H.; Chia, F.S. Sustained delivery of paclitaxel using thermogelling poly (PEG/PPG/PCL urethane) s for enhanced toxicity against cancer cells. Journal of Biomedical Materials Research Part A 2012, 100, 2686-2694, https://doi.org/10.1002/jbm.a.34198.

108.Tian, B.; Hua, S.; Liu, J. Cyclodextrin-based delivery systems for chemotherapeutic anti-cancer drugs: A review. Carbohydrate polymers 2020, 232, 115805, https://doi.org/10.1016/j.carbpol.2019.115805.

109.Erdagi, S.I.; Yildiz, U. Diosgenin-conjugated PCL-MPEG polymeric nanoparticles for the co-delivery of anti-cancer drugs: design, optimization, in vitro drug release and evaluation of anti-cancer activity. New Journal of Chemistry 2019, 43, 6622-6635, https://doi.org/10.1039/C9NJ00659A.

110.Li, C.; Dai, J.; Zheng, D.; Zhao, J.; Tao, Y.; Lei, J.; Xi, X.; Liu, J. An efficient prodrug-based nanoscale delivery platform constructed by water soluble eight-arm-polyethylene glycol-diosgenin conjugate. Materials Science and Engineering: C 2019, 98, 153-160, https://doi.org/10.1016/j.msec.2018.12.078.

111.Al-Karaki, R.; Awadallah, A.; Tawfeek, H.M.; Nasr, M. Preparation, Characterization and Cytotoxic Activity of New Oleuropein Microemulsion Against HCT-116 Colon Cancer Cells. Pharmaceutical Chemistry Journal 2020, https://doi.org/10.1007/s11094-020-02133-X.

112.Mei, L.; Zhang, Y.; Zheng, Y.; Tian, G.; Song, C.; Yang, D.; Chen, H.; Sun, H.; Tian, Y.; Liu, K. A novel docetaxel-loaded poly ( $\varepsilon$-caprolactone)/pluronic F68 nanoparticle overcoming multidrug resistance for breast cancer treatment. Nanoscale research letters 2009, 4, 1530-1539, https://doi.org/10.1007/s11671-009-94316.

113.Song, Z.; Zhu, W.; Liu, N.; Yang, F.; Feng, R. Linolenic acid-modified PEG-PCL micelles for curcumin delivery. International journal of pharmaceutics $\mathbf{2 0 1 4}, \quad 471, \quad 312-321$, https://doi.org/10.1016/j.ijpharm.2014.05.059. 
114.Li, X.; Li, R.; Qian, X.; Ding, Y.; Tu, Y.; Guo, R.; Hu, Y.; Jiang, X.; Guo, W.; Liu, B. Superior anti-tumor efficiency of cisplatin-loaded nanoparticles by intratumoral delivery with decreased tumor metabolism rate. European Journal of Pharmaceutics and Biopharmaceutics 2008, 70, 726-734, https://doi.org/10.1016/j.ejpb.2008.06.016.

115.Tabatabaei Mirakabad, F.S.; Akbarzadeh, A.; Milani, M.; Zarghami, N.; Taheri-Anganeh, M.; Zeighamian, V.; Badrzadeh, F.; Rahmati-Yamchi, M. A Comparison between the cytotoxic effects of pure curcumin and curcumin-loaded PLGA-PEG nanoparticles on the MCF-7 human breast cancer cell line. Artificial cells, nanomedicine, and biotechnology 2016, 44, 423-430, https://doi.org/10.3109/21691401.2014.955108.

116.Wan, K.; Sun, L.; Hu, X.; Yan, Z.; Zhang, Y.; Zhang, X.; Zhang, J. Novel nanoemulsion based lipid nanosystems for favorable in vitro and in vivo characteristics of curcumin. International journal of pharmaceutics 2016, 504, 80-88, https://doi.org/10.1016/j.ijpharm.2016.03.055. 